.63 


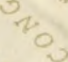

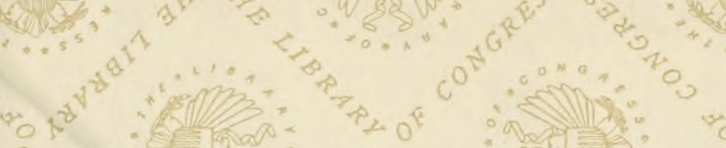

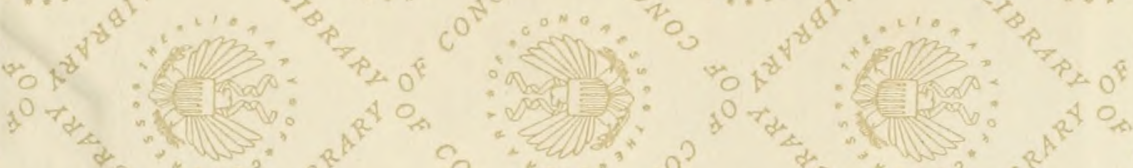

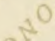

150

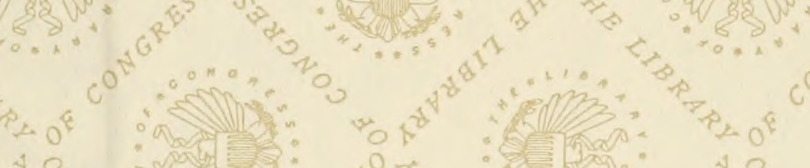
(1) (1) (N) a

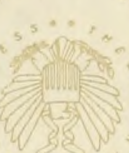
(2)

Nitar

श्रेत्य

$0^{2}$

$x^{0}+4$
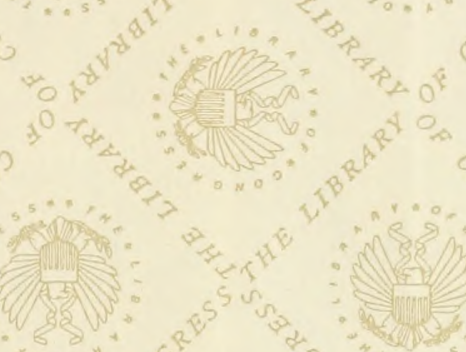






\section{THE BACTERIOLOGY OF THE FEMALE REPRODUCTIVE ORGANS OF CATTLE AND ITS RELATION TO THE DISEASES OF CALVES}

\section{A THESIS}

PRESENTED TO THE FACULTY OF THE GRADUATE SCHOOL OF CORNELL UNIVERSITY FOR THE DEGREE OF

\section{DOCTOR OF PHILOSOPHY}

BY

CHARLES M. CARPENTER 


$$
{ }_{S^{3}} \mathrm{C}^{871}
$$

Byexchange Amell Unior. Ditrany 


\title{
THE BACTERIOLGY OF THE FEMALE REPRODUCTIVE ORGANS OF CATTLE AND ITS RELATION TO THE DISEASES OF CALVES
}

\author{
Charles M. Cabpenter \\ Department of Pathology and Bacteriology
}

New York State Veterinary College at Cornell University, Ithaca, N. Y.

Perhaps the most important diseases in animal pathology, or those receiving the most attention at least at the present time, are the pathological conditions associated with the breeding of cattle. From a study of the reproducrtive efficiency in many large herds, Williams (1) has found that it is about 60 per cent of the ideal. The ideal which he considers normal and which herds, especially dairy herds, should strive to attain, is that each female in the herd should produce one living calf every twelve months, and that each heifer throw her first calf at two years of age. The U. S. Department of Agriculture placed the losses from observed contagious abortion at $\$ 20,000,000$ for the year 1915 (2). A conservative estimate of all losses from infections associated with the breeding of cattle is 25 per cent, and since the valuation of all the eattle in the U. S., as reported January 1, 1921, is $\$ 1,934,185,000 \quad(3)$ one can readily judge the enormous economic loss to the country. Moreover great losses are caused by these diseases in connection with the work of improving the breeds and from a scientific point of view, by reason of the breaking up of experiments in heredity.

The importance of the bacterial content of the genital canal can easily be estimated from the foregoing statements. Much confusion has arisen in the past, and still exists, inasmuch as many observers in this field have studied the infections occurring in the diseased conditions without any knowledge of the microorganisms that may exist in the healthy reproductive organs of cattle. This is true of almost all the diseases that have been under close observation because it is primarily the abnormal condition that attracts the attention of the investigator.

Because of the widely varied opinions concerning the different miccoorganisms existing in the reproductive organs and their relation to the etiology of the diseases associated with them, it has seemed advisable to make a thorough bacteriological investigation of these organs, covering all ages and conditions, in an effort to improve the general conception of this subject and to correlate the facts with more accuracy. This work, started in the fall of 1917 , has been carried on systematically and in great detail for nearly four years. In it I have tried to determine six things: First, what microorganisms, if any, normally live in the organs comprising the female genital tract of cattle? Second, at what age of the animal and by what channels do the organisms enter the genital canal? Third, what relationship exists between these microorganisms and the pathological changes associated with them? Fourth, what effect is produced by these organisms on the fetus in the pregnant uterus, or on the calf at birth? Fifth, is there any evidence that bacteria which may have been transmitted to the calf from the dam lie dormant in the former until breeding age? Sixtb, if these bacteria do persist until breeding age, is their habitat the genital tract or do they become localized elsewhere in the body thence proceeding to the reproductive organs st puberty and first pregnancy?

\section{HISTORY}

In reviewing the literature dealing with the bacteriology of the female genital tract of man and animals, one can find in human and veterinary medicine very little work which has been done upon these diseased tissues. As a result of the losses from puerperal fever in women, when aseptie methods were not understood and observed as carefully as they should have been, special attention was paid to the bacterial flora and chemical reaction of the vaginal secretions of pregnancy and non-pregnancy. The relation of the microorganisms found to the etiology of puerperal fever has been discussed at great length. Chief among the workers have been Döderlein (4), Williams (5), Krönig (6), Winter (7), Bensis (8), Bergholm (9), Walton and 
Medalia (10), Küster (11) and Permar (12). These men did not agree entirely in their conclusions but in the main they found that in women the normal vaginal secretion is acid, as tested out with litmus paper, and because of this acidity very few bacteria are capable of living in the vagina. Döderlein reports that the acidity is due to a microorganısm which he has described and which is called Döderlein's bacillus. He carried on experiments with this organism to prove the point but some of the other workers did not agree with him. These men also stated that when the secretion contains large numbers of leucocytes, squamous epithelial cells, and bacteria, they consider it pathological. Under these conditions the reaction of the vaginal content approaches the neutrality point and in some cases it even becomes alkaline, in which case the bacteria are able to thrive. Krönig examined 300 cases and reported that the reaction of all these secretions was acid and that there were no streptococci present. He stated that this was the result with the pathological as well as with the normal secretions. Besides the gonococcus, the organisms found were for the most part streptococci, staphylococci, the thrush fungus (Oidium albicans) and occasionally a few rods. Sometimes they were found to be pathogenic for laboratory animals, but they often produced no effect upon them and because of this fact some of the investigators considered the organisms to be in a state of low virulence. The streptocococcus was thought to be most important because of its close relation to puerperal fever. I have come across no systematic bacteriological studies on the flora of the upper part of the healthy genital canal of women, although some work has been done on the bacteriology of cervicitis, endometritis, salpingitis and ovaritis by Rosenow (13), Davis (14), Miller (15), Grad (16), Curtis (17) and Tweedy (18).

In veterinary medicine even less work has been done on the bacterial flora of the reproductive organs of domestic animals than can be found in the literature having to do with human medicine. There has been an abundance of material, both normal and abnormal, contrary to the conditions found in human medicine, but no one has availed himself of the opportunity. Because of great losses of calves from various calf infections, some work has been done with the bacterial content of the vaginæ of cattle, inasmuch as some of the early investigators believed that the calf became infected during the process of parturition. In 1904 Denzler (19) did considerable work on the bacteria commonly found in the vaginæ of cattle and also some bacteriological work on the entire genital tract. He recorded staphylococci, streptococci and organisms from the colonaerogenes group in the vaginal vestibulum but stated that these bacteria are not able to grow within the healthy vagina. He considered the external os uteri as the normal barrier between the germ-free zone in the genital canal and the zone which harbors bacteria, if, under abnormal conditions, the vagina contains bacteria. After a long series of experiments he concluded that the vaginae of calves, pregnant and non-pregnant cows possess a power to disinfect themselves if microorganisms accidentally enter or are introduced therein. Experimentally he found this bactericidal action to be permanent, taking the tissues from 18 to 117 hours. He was of the opinion that the leucocytes, acting as phagocytes, and not the chemical reaction of the vaginal secretion, are the agents which destroy the bacteria. He stated further that the cervical canal, the uterus and the tubes are normally free from germs.

In 1919 Giltner and Bandeen (20) compared the bacterial findings from ten puerperal uteri with those from the meconia of calves from the same uteri. They say, "Thirty-four organisms were isolated from the vaginae and twenty-four from the uteri. There were fifty-two different organisms isolated, only five of which occurred in both uterus and vagina. There were no two cows which showed an identical flora in either uterus or vagina, and there was very little similarity in the bacterial flora of any two cows, although they were all on the same premises *****

"Of the organisms found there were, of the four genera according to Migula, bacterium, 22 ; bacillus, 3 ; micrococeus, 11 ; streptococcus, 4."

The bacteriology of the fetus and newborn infant is not uniform. It has not been carried out methodically in most cases and the investigator in human 
medicine has had access in the newborn iniant only to those cavities which communicate with the exterior from which to make cultures. These cavities are the mouth, rectum and vagina. VonReuss (21) states that staphylococci are invariably present in the infant's mouth when they are present in the vagina of the mother. The streptococei are less frequently tound. Kneise (22) reached the conclusion that $100 \%$ of infants are born with bacteria in the mouth and that Staphylococcus aureus greatly predominates over the streptococcus. Knapp (23) reported finding a close relation between the bacterial flora of the vagina and intestine of the newborn. Schmidgall (24) found that in most cases the buccal cavity was free from bacteria for the first 24 hours, although in a few cases she found hemolytic streptococci in the rhild's mouth as well as in the vaginal secretion of the mother during labor. She concluded that the raginal flora in the newborn female depends upon the vaginal flora of the mother. The lrench investigators, Bunnaire, Keim, Jeannin and others, quoted by Mme. Brailowsky-Lounkevitch (25), reported that the buccal fluid of the newborn is sterile. Smith (26) found staphylococci and streptococei in the vaginae of infants at a very early period after birth. The results of the work of Hymanson and Hertz (27) on the bactericlogy of the parturient vagina and the mouth and rectum of the newly born are practically the same as those of the French workers.

Various investigators have cultured the meconia of infants and have reported conflicting results. Some have found that the meconium is negative at birth, while others have isolated numerous bacteria. Very little detailed bacteriology has been carried out on the fetuses of domestic animals. The greatest amount of this work has been done on the bovine fetus and is comparatively recent. When Bang (28) in 1896 first described the organism which is now called Bacterium abortum, he reported finding it in the tissues of the fetus. Besides a group of fetuses from which Smith (29) isolated Bacterium abortum, he mentioned three other groups, "(a) the few fetuses yielding sterile cultures, (b) those yielding rapidly growing cultures of colon-like and other bacteria, and (c) those yielding pure cultures of a spirillum." Practically all of the work on bovirie fetuses mentioned above has been carried out on fetuses expelled prematurely or dead. I have found almost no literature dealing with the bacteriology of the genital tracte of either the healthy or diseased fetus.

\section{TECHNIC}

The technic which I have used in this work has been varied greatly during the four years. Practically every method of isolating microorganisms has been tried and very many different media have been experimented with. Мy main object has been to improve the technic, i. e., to make it less complex, to decrease errors from contaminating bacteria, and to find the best media upon which the largest number of organisms will grow. In any case many errors will arise and it is almost impossible to interpret results in precise terms.

With the exception of the material obtained from the abattoir, all has come from herds located in six of the eastern states. The genital tracts from the cows and veal calves were removed in the following manner: After the animal was slaughtered and skinned, the posterior parts were elevated about four or five feet above the floor. An incision was made along the linea alba. to allow the abdominal viscera to escape, after which the symphysis pubis was sawed through. An area around the genital tract was flamed with a gasoline torch. Then an incision was made through the recto-vaginal pouch and other folds of peritoneum between the rectum and vagina, four or five inches anterior to the vulva. A stout cord was passed through the incision around the vagina and tied securely. An assistant pulled centrally on the cord while all of the attachments of the genital tract were severed with a sterile knife and wrapped immediately in a sterile towel. In some cases, when an assistant was not at hand, the vulva was grasped with a pair of Bozeman's forceps, or other long forceps, held in the left hand, while the attachments were being severed. The only time that the genital organs came into contact with the hands or other possible infection carrier was when the cord was placed around 
the walls of the vagina and during the exposure for a very short time to the bacteria of the air before wrapping in the sterile towel. The tracts were then taken to the laboratory where cultures were made, smears of the different parts made on glass slides, and sections of the different organs taken for pathological study.

Cultures were made from the ovaries, oviducts, right and left uterine apices, body of the uterus, cervix, and in most cases from the vaginal folds around the external os uteri. 'The mammary gland was cultured in many cases. About forty cultures were made from each adult genital tract. Four cultures were made from each part. At first two aerobic and two anaerobic cultures were made, but later cultures grown at partial oxygen tension were made because no strict anaerobes were recovered. The ovarian cysts and cystic curpora lutea were cultured with a sterile, sharp-pointed pipette which was pushed through the cyst wall after an area on the latter had been sterilized with a heated platimum spatula. As a rule the cultures from the cystic lluid were negative and, because of this Rosenow's (30) tissue crusher was used to erush the whole ovary or as large a section of it as could be placed in the crusher. C'ultures were then made from the material that was ground up. This method is inconvenient for crushing cows' uvaries becãuse the ovaries, especially those which are diseased, are too large as a rule to be placed in the crusher without sectioning and it is diffoult to havdle them so much without contamination. The simplest plan is to sterilize an area on the surface of the ovary with a heated platinum spatula, and with a fine pair of sterile forceps to tear out a small piece of the ovarian tissue about the size of a pea or smaller, and to place this on the medium. At times it is desirable to make cultures from the adhesions on the capsule of the ovary and this can be done in the same way without sterilizing the tissue, if the ovary has been handled under aseptic conditions. Generally if an organism can be isolated from the adhesion around an ovary, it can also be isolated from the ovarian tissue itself and it is not necessary to make cultures from both areas except for verification.

The oviducts were cultured by sterilizing an area with a heated spatula and then making an incision into the lumen with a sterile platinum loop. Cultures were made through the fimbriated end of the tube if the latter was not adherent to the ovary. When the genital tracts of smaller animals were cultured, the lumen of the oviduct being tou small for cultures, the wholp orary and oviduct on one side were crushed in Rosenow's tisite ('rusher or ground up with sterile sand in a mortar with a pestle.

The apices and body of the uterus were cultured by tearing out a piece of the uterine wall, after sterilizing an area from which cultures were to be taken and making an incision through the wall with a sterile knife. If there were fluids in the uterus. they were withdrawn in storile pipettes and plated on the medium. If the mucosa only was touched with a platinum loop and a bit of the glandular secretion placed on the medium, there was a failure as a rule to get a growth. The organisms, especially the streptococcus. apprared to be living in the depthe of the tissue, as the submucosa, and not on the surface of the mucosa. We have demonstrated this, i. e., the streptococcus to be in the submucosa, in several preparations from sections and smears from the uterine wall, especially in chronic conditions.

Cultures were taken from the cervical canal by sterilizing an area on the lorsal surface of the cervix, midway between the external and internal os nteri, with a heated spatula or a gas flame or torch. An incision was made with a sterile knife into the canal and a piece of the mucosa and submucosa was torn out with fise sterile forceps and placed on the medium.

The anterior folds of the vagina and external os uteri were enltured in the same manner as described above. In calves and fetuses the mucus in the ragina was withdrawn with pipettes and cultured. The vulva and posterior part of the vagina were not cultured in all cases because much work has already been done on these parts and it was an impossibility to care for so many cultures from such a fertile field. Then, too, it was found that the hacterial flora of the posterior part of the vagina and rulva varied in different herds. 
When pregnant uteri were cultured, the same procedure was carried out with reference to the ovaries and oviducts. The fetal fluids were cultured and the fetal and maternal cotyledons, if these were large enough to secure pieces of the tissues. The apices and body of the uterus were cultured at the utero-chorionic space and tissues were also removed from the walls at these points. A piece of the cervical seal was removed, as described above, and cultured. Cultures were made from the anterior folds of the vagina as in the case of the non-pregnant uteri.

For the most part the fetuses and calves were brought or shipped into the laboratory and post mortem examinations and cultures were made there. The alimentary tract was cultured at several different places by means of sterile pipettes, after sterilizing an area with a lieated spatula, isually the rumen, abomasum, small intestine, caecum and rectum were eultured. 'The heart's blood, lungs, liver, spleen and genital tract were cultured also. The heart's blood was cultured hy means of a pipette while the cultures from the other organs were made by placing a piece of tissue on the medium.

When cultures were to be made from living ablves immediately after birth. the latter were handled as follows: The eow was placed in a clean disinfected stall just before the calf was born. Her posterior parts were washed thoroughly with a disinfectant and sometimes an entire hath was given. The cali was caught on a large piece of canvas which had been soaked for a long period in a strong disinfectant. Immediately after expulsion a sterile, soft rubber, horse catheter with a piece of glass tubing in which was a cotton plug. was inserted in the back of the calf 's mouth and pushed down the enopharus to the stomach. (It is necessary to have an assistant with aseptic hands hold open the calf's mouth.) Then the contents of the stomach were sucked up into the tube and the contents allowerl to escape into a sterile container. The meconium can be collected in a similar manner. The anus of the calf should be disinfected, a sterile, soft rubber, horse catheter inserted into the rectum for a distance of 18 to 20 inches, and sterile water or saline solution from an irrigator run into the bowel and the meconium forced out. The meconium, which is usually covered with a tough mucous coat, should be collected in large sterile Petri dishes or other containers and cultured. The curface of the meconial nuss can be sterilized with a heated platinum spatula and material from the center of the mass placed on the medium.

Two or three smears were made upon glass slides from nearly every tissue from which a culture was made. The smears were stained with methylene blue for various lengths of time, from five minutes to forty-eight hours. Duplicates also were stained with Gram's stain and sometimes carbolfuch-in was used. This was done to check up the cultures in case dead lacteria should be present or living organisms which were not being recovered in culture.

Samples of blood were drawn from nearly all animals and the serum set with an antigen made from Bacterium abortum. Each genital tract of the fetuses and calves was carefully deseribed at the time when eultures were made.

Smillie's (31) method of injecting Guinea pigs and isolating Bacterium abortum was employed quite generally with the different tissues from which cultures were made. As a rule extracts from ovaries and ovidicts were not injected but contents of the uteri, extracts from uterine walls, cervical seals, vaginal secretions and fetal fluids, extracts from fetal membranes, and contents of the alimentary tracts of fetuses, as well as extracts from other tissues, were injected. One extract was made from the lung, liver and spleen of a fetus and another from the genital tract. These extracts were ground un in sterile mortars with sterile sand and a sterile saline solution, then filtered through cotton. One or two e.e. were injerted subentaneously acending to the size of the pig and the dilution of the extract. In cases where it was possible to oltain samples of milk. the were centrifuged down and the serliment injected into the pigs. In three or four weeks the pigs were slaughtered by placing them in jars filled with artificial illuminating gas. Each pig, with its abdomen dorsal, was than stretched on a board * and

* The construction of this board was suggested to me by Dr. H. Inffman. 
fastened to it by means of four nail points arranged at angles at each corner of the board, each nail piercing a leg of the pig. The board (See Plate 1 ) is easy to construct and saves much time when large numbers of guinea pigs are to be examined, for it does away with the tying of strings or fastening of clamps as is the case with most animal holders. Br this method we have been able to slaughter and culture about twelve pigs in an hour.

The hair on the abdomen was singed ofl with a gas flame, the charred hair scraped off, and the surface swabbed with $5 \%$ solution of phenol. An incision was made on the median line and the right thoracic and abdominal walls cut away. This allowed the intestinal tract to be removed easily, as shown in Plate II. Then with sterile forceps and a knife, the spleen, liver, and uterus or testes were removed and placed in sterile Petri dishes. Cultures were made from these organs by placing a piece of tissue upon the medium. The cultures were sealed with wax, as Smith suggests, incubated and treated according to the last method described under the different methods of producing partial oxygen tension. A sample of blood was taken from each pig and set with an antigen made from Bacterium abortum.

When the work was first hegun, aerobic and anaerobic cultures were made from the different tissues. Liborius' (32) method for making the anaerobic cultures was used. Cultures grown under partial oxygen tension were made and altogether four different methods were tested. "First. Nowak's (33) method of placing cultures in an atmosphere where $B$. subtilis was growing: second, Wright's (34) method with prrogalic acid and $0.1 \%$ solution KOH (one part liquor kali, canst. to ten part $\mathrm{H}_{2} \mathrm{O}$ ).

A third method is the following: Culture tubes are placed in large jars with ground glass stoppers. An alcohol lamp is set in the jar and fighted. raseline is smeared over the ground surface of the cover and the cover placed on the jar. It is necessary to have a hole, 3 to $4 \mathrm{~mm}$. in diameter, bored in the cover. Before placing the latter in position, the hole can be filled with sealing wax. The flame burns only until the nxygen has been consumed and a vacuum has been created. When the cultures are to be examined, great difficulty will be experienced in removing the cover unless the sealing wax is removed first to allow air from the outside to rush in and replace the vacuum.

The fourth method is as follows: The cotton stoppers of the culture tubes may be sealed either with paraffin or sealing wax. In sealing tubes with wax, (are should be taken not to push the plug below the mouth of the tuhe because. otherwise it is hard to remove the wax without breaking the tube when the latter is opened for examination. The plan is to form a cap over the cotton plug without allowing any wax whatsoever to drop inside the mouth of the tube. Before sealing the tube, the stopper should be trimmed and flamed. This allows the hacteria which have been placed on the medium, access only to the oxygen in the air sealed up in the tube.

The best results have been obtained from sealing the tubes with wax or paraffin. There is much less labor involved when paraffin is used but it means very dirty, disagreeable work when the cultures are examined. Nowak's and Wright's methods, as well as the covered jar with the alcohol lamp, are somewhat complicated and cumbersome. It was found that they produced a good partial oxygen tension for growing Bacterium abortum but so much condensation water formed in the jars that the growth of streptococci was inhibited to a certain extent.

Many different media have been used throughout the work. For a long time duplicate cultures were made on various media and grown under diverse methods, until we were certain which medium and which method was the hest. Cultures were made on ordinary nutrient agar, solidified hovine serum. Loeffler's (35) hlood serum. gluose glycerine agar plus sterile bovine serum. Huntoon's (36) hormone agar, splenic extract boullon, ovarian extract bouillon, and uterine extract houillon. All these were prepared in the same mamner as ordinary peptonized bouillon. Agar was made also, according to Huntoon's method, from the spleen, ovary and uterus as well as from genital tracts in early stages of pregnancy. the fetal fluids and membranes being ground up with the other tissues. Ordinars nutrient real agar. or nutrient agar made from peptomized heef houllon. upon which has heen placed either 
a little sterile serum or a few sterile blood corpuscles collected from a horse, cow or calf, has been employed extensively and with very good results. The Hydrogen-ion concentration of the culture medium seemed to play an important part, especially in the cultivation of the streptococcus. At first a medium was used with Hydrogen-ion concentration of $\mathrm{pH}$. 6.5 but it was found that media at $\mathrm{pH} .7$ or 7.5 was much more satisfactory.

In many instances we did not use the blood corpuseles or serum but. instead, a piece of tissue, from which the eulture was made, was placed on the medium. The object is to have some fresh enriching material to favol the start and growth of the organism transplanted with the tissue. This combination, i. e., nutrient agar $(\mathrm{pH}, 7-7.5)$ with some enriching substance such as serum, blood corpuscles, or a piece of fresh tissue, and cotion stoppers sealed with realing wax, has given very favorable results and has yielded growths when other media have failed to do so.

All cultures were incubated at 37 degrees C. Examination was made 24 to 48 hours after incubation and if no growths were observed, the wax caps were removed and the tissue or other material which had been introduced into the medium was smeared over the surface of the latter and pushed down again into the condensation water. The stoppers were resealed and the tubes placed back in the incubator. If in 48 hours more no growth appeared, the same process was repeated. It is surprising to find how many more growths can be obtained by this procedure. This is especially true in the case of the streptococcus and Bacterium abortum. If no growth appeared after 10 or 12 days, the cultures were discarded.

\section{Bacteriological Findings}

In order to simplify the work, all the animals whose genital tracts have been cultured have been divided into six groups. Group l consists of genital tracts from pregnant cows. Group II comprises genital tracts from nonpregnant uteri. Group III is virgin heifers. Group IV is made up of ealves from 3 to 12 weeks of age; Group $V$ consists of ealves 1 to 3 weeks old; and Group VI of aborted fetuses or those removed from pregnant uteri. More work has been done on Group II than on the other groups because of the greater ease with which the non-gravid tract is obtained. The majority of these have been cows with abnormal breeding histories. An abundance of material could be had from local slaughter houses and larger abattoirs but one is handicapped with such material because he knows nothing of the history of the animals. The history has been considered an important factor, especially in connection with the work on the non-pregnant genital tracts. Many tracts in which conception had not occurred have been observed, without apparent lesions, at least nothing that is considered pathological at the present time could be found. Other factors which might have caused failure to breed, such as a diseased male, had been eliminated. Therefore, in considering a normal genital tract for bacteriological examination, the breeding history seemed very important but we found that it was difficult to obtain such information.

The genital tracts of 139 females have been examined and in nearly every case each organ of the tract was cultured. The following divisions were made: Genital tracts from pregnant animals, 11; normal genital tracts from non-pregnant animals, 19 ; abnormal genital tracts from non-pregnant animals, 50; genital tracts from virgin heifers, 10 ; calves $3-12$ weeks old, 12; calves 1-3 weeks old, 9; aborted female fetuses, 13: aborted female fetuses whuse dams were injected with Bacterium abortum, 2: normal female fetuses, 11; female fetuses removed from cows suffering from dystocia, 2 . Twenty-four male fetuses, normal, aborted, and dystocia cases were examined. Besides culturing the genital tracts of the fetuses and calves 1-3 weeks old. a bacteriological examination was made of the tissues from the rest of the animals.

The results of this bacteriological investigation have been extremely interesting. The exact locations of organisms isnlated from different parts of the genital canal mas be seen on the charts. In many cases all of the cultural 
characteristics of an organism have not been worked out farther than identifying it according to Migula's classification. It is often impossible to obtain a subculture of an organism from the primary growth. A complete study of the characteristies of certain of these organisms will be carried out in detail and published later.

The cultures from the genital tracts of the 11 pregnant animals (Group I Chart I) were uniformly negative in five ases. Bacterium abortum was isolated from the fetal fluids of one animal while the other cultures from this tract were negative with the exception of the vagina where $B$. coli was found. Number 6 was negative with the exception of the right uterine apex in which there was an unidentified rod, and the vagina in which were $B$. coli and staphylococcus albus. Tract 8 gave pure cultures of a streptococcus from nearly every organ, while in Tract 2 growths were obtained only from the uterus and cervix. In the uterus of Tract 3 streptococei mixed with Ps. pyocyaneus were found in the uterus; the external os uteri yielded only a streptococeus. The ovaries and right oviduct of Tract 11 gave cultures of streptococcus viridans in conjunction with staphylococci. From the anterior folds of the vagina of this tract also was obtained a culture of Staphylococcus albus.

Group II (Charts II, III), in which I have included 69 non-pregnant animals, is of unusual interest. Eighteen are reckoned as normal tracts and fifty-one are either pathological or came from cows with abnormal breeding histories. Of the 18 normal genital tracts, 5 yielded no growths, while 6 gave rultures from the uterus only, the remainder of the tracts being negative. Four tracts showed cultures of a streptococeus from some part of the uterus and also from one of the oviducts. In one case the streptococeus was mixed with a staphylococ'us albus. Another tract vielded growths of a streptococeus and Staphylocoocus albus from the ovaries and ovirtucts and Ps. pyocyaneus from the uterus. Still another tract gave cultures of Staphylococeus albus from the oviduct and a Gram negative unidentified rod from the cervix. Tract 54 was negative with the exception of a staphylococcus aureus from the cervix.

Under Group II are also included 17 animals slaughtered in one herd. These cows varied greatly in age, 4 being heifers that had never conceived though bred many times. All had been donched regularly and otherwise treated for sterility for many months. Cultures were obtained from some portion of each tract. All of the organisms isolated from these animals fell in the group of streptococei, with the exception of $B$. coli which was found once in the anterior part of a vagina. The majority were streptococei coming chiefly from the oviducts and ovaries. Occasionally a pure culture of a streptococeus was recovered from the anterior portion of the vagina, the cervix or the uterine apices. In a few cases a staphylococcus was recovered in pure culture from the various organs of the genital canal hut usually a streptococcus was found with it. A sacharomyces was isolated from the uterus of one case, Number. 48.

The remaining 34 genital tracts from Group II were collected from 17 various herds which in most eases were long distances apart, 100 to 300 miles or more. With the exception of Tracts 36, 66 and 67, which were olotained from the abattoir and the history of which was not known, and of two cases of pyometra, all of these cows were slaughtered after being condemned for incurable sterility. All had received various kinds of treatment for overcoming this condition. For the most nart the bacteriological findings were cimilar to those of the alove mentioned 17 cows. The predominating organisms were coeci, chief among them heing the streptoeocus. Staphyloeneei and occasionally a sarcina were recovered but in nearly every case these were found in conjunction with the streptococcus. Only three tracts $(8,9,61)$ from this series gave negative results and in onl r nne were growths anfined to the uterus alone. In the oviduct of one cow (39) a paracolon organism was found and in a case of hydrosalpinx (2), an organism from the colonaerogenes group was isolated in pure culture. Barillus muonenes and Barillus. aerogenes capsulatus were recovered respectively from two cases of prometra (21 and 24) but in each case a streptecoceus was found with the oroganisms named. Bacterium abortum was found in the udder of one heifer (4) that 
had nerer conceived. A hemolytic streptococcus and Bacterium abortum were isolated from a tract $(36)$ which was aflected with granular venereal disease. Occasionally spore-bearing rods have been recovered from the cervix and several times from other parts of the genital canal. In one or two cases other unidentified rods have been recovered in cultures. A fungus also has been isolated in one or two instances.

Group III (Chart IV), which is comprised of virgin heifers, showed fewer bacteria than the groups of pregnant or non-pregnant animals. Six of the ten heifers failed to show any growths, while one $(\tau)$ yielded a spore-bearing rod from the cervix. Number 2 showed a streptococcus in hoth tubes and apices of the uterus, while $s$ showed two strains of streptococei, streptococcus virdans and Streptococeus hemolyticus (Beta), in the uterus, and a growth of streptococcus viridans in the external os uteri. Number 10 showed Streptococcus viridans in both ovaries and in the body of the uterus.

Group IV (Chart V) consists of 12 calves from 3 to 12 weeks of age. The udders of calves and fetuses were cultured more frequently than were those of adult animals. There was practically no glandular tissue present but, after cutting off the teats, pieces of the fat and connective tissue were removed with sterile forceps and placed on the media. The genital canals of eight of these animals yielded no growths of microorganisms although Bacterium abortum was recovered from the udder of Number 9, which is included in this group. In three cases $(3,4,10)$ streptococei were isolated from the ovaries. In two instances (3, 10) they were associated with staphylococcus aureus. Number 4 gave growths of Staphylococcus aureus, albus and Streptococcus viridans from the vagina, while the vagina of number 10 gave a pure culture of $B$. coli. From the uterus of Number 10 was isolated Bacterium abortum. The tract of Number 2 was negative with the exception of Streptococcus viridans in the vagina.

Group V (Chart VI) is made up of genital tracts removed from calves 1 to 3 weeks old dying from various types of ealf infections, such as pneumonia, enteritis, etc. Six of these tracts failed to show any bacteria. Case 6 gave pure cultures of staphylococous albus from the uterus, the rest of the tract being negative.

Group VI (Charts VII, VIII, IX, X, XI), in which I have included 62 fetuses ranging in age from 30 days to 9 months, is comprised of 23 fetuses removed from pregnant uteri, 25 aborted fetuses, 5 aborted fetuses whose lams were injected intravenously with Bacterium abortum, 6 fetuses that were removed from cows suffering from dystocia, and 3 mummified fetuses. The charts upon which the bacteriological data for this group are given show from what tissues, besides the genital tract, microorganisms were isolated.

In the case of the 23 fetuses removed from pregnant uteri, the majority appeared normal, although the exact result of the pregnancy, had the fetus remained in utero, cannot be known. Bacterium abortum was recovered from three of these fetuses. In one of these. Number 26, streptococcus viridans also was isolated from the meconium in the reotum, while Bacterium abortum was not found there. Cultures of streptococei were obtained from 8 fetuses, although in five cases they were found in conjunction with Staphylococcus aureus or albus. Four fetuses yielded growths of staphylococci, while 8 failed to show growths of any organism.

Bacterium abortum was reeovered from 10 of the 25 aborted fetuses (Chart VIII). In 4 cases strphylococcus albus or aureus was recovered. Streptococei were isolated from 6 fetuses, 4 eases of these yielding no other organism, while in two cases. 15 and 16 , organisms from the colon-aerogenes group were recovered. The stomach contents of Fetus 15 contained a fungus also but this fetus was expelled alive and had swallowed much extraneous material. A Gram positive spore-bearing rod was recovered from the liver of Fetus 2. Staphylococei and organisms from the colon-aerogenes group were recovered from Fetus 4, which was expelled alive. Fetus 33 yielded pure cultures of $B$. prodigiosus from the heart's blood and small intestine. A hemolytic Staphylococcus albus was isolated in pure culture from Fetus 34. From the 
stomach contents and intestinal tract of Fetus $5 \pm$ was recovered a very interesting fungus, and staphylococcus albus was found also. A Gram positive organism similar to $B$. pyogenes and from which I was unable to get a growth, was observed in smears from the viscera of Fetus 58 , which was only $11 / 2$ months old. The uterine exudate from the dam gave a pure culture of 13. pyogenes and the organism in the fetus was apparently the same. Fetus 6I gave a pure culture of a short Gram positive rod, which has not been identified, from the stomach contents. Only two fetuses in this group failed to give growths of any organism.

On Chart IX are tabulated the bacteriological findings of jotuses whose dams were injected intravenously with Bacterium abortum. This organism was recovered from some part of each fetus but was found in pure culture in only one case. In the other four cases staphylococci also were recovered and in Fetus 32 . Streptococcus viridans was found.

Two of the six fetuses which were removed from cows suffering from dystocia (Chart $\mathrm{X}$ ) failed to show any bacteria in cultures. Fetus 5 gave a growth of streptococcus viridans and a staphylococcus albus (hemolytic). lrom all the tissues of Fetus 31 a fungus was recovered. Fetuses 55 and 56 were twins and from the tissues of both of these an organism that was either B. paratyphoid. $B$ or $B$. enteriditis was recovered. Fetus 31 showed extensive emphysema. The others failed to show any signs of this condition.

Chart XI gives the bacteriological data from three mummified fetuses. Fetus 20 gave cultures of streptoroceus viridans and from the spleen an unidentified Gram negative rod was recovered. An organism from the colon-aerogenes group was recovered from Fetus 49, while Fetus 51 showed the same organism in pure culture. Guinea pigs inoculated with extracts of the tissues from this fetus, however, showed typical lesions of Bacterium abortum and it was recovered in pure culture from their spleens and livers.

The bacteriology of the genital tracts of the fetuses has been of umusual interest. As a rule the distribution of the bacteria throughout the genital 'anal of the fetus cannot be traced as well as in the adult because of smaller size of the former. The cultures that were isolated directly on the media came for the most part from the uterine cavity, although in some cases Bacterium abortum was not recovered in culture but from guinea pigs that had been injected with extracts made from the genital tract. No cultures were isolated from the vaginae of the fetuses. In no case were bacteria recovered from the male or female genital tracts of fetuses removed from pregnant uteri. The genital organs of 8 female and 7 male aborted fetuses were negative. Bacterium abortum was recovered from the reproductive organs of 3 females and 2 males, the organism being found in conjunction with Staphylococcus aureus in the case of one female. The genitalia of 2 males whose dams were injected with Bacterium abortum were negative. while the genital tract of a third male yielded Bacterium abortum and Streptococcus vividans. From the genital tracts of two females in this group Bacterium abortum was recovered but in the case of one of them. Fetus 39, streptococcus viridans, staphylococcus albus and Staphylococens aureus were also recovered.

The results were negative from the genital tracts of one female and two male fetuses that were removed from cows suffering from dystocia. A fungus was recovered from the testes of one male. 'This fungus was also isolated from the other tissues of the fetus. The genital organs from the pair of twins, Fetuses 5.5 and 56 , a male and female in this group, gave puru cultures of $B$. parctyphoid $B$ or $B$. enteriditis but, as mentioned before, the same organism was also recovered from the other organs of these fetuses. The hacteriology of the genital trarts of the mummified fetuses could not be worked out satisfactorily.

The different microorganisms isolated have in a general way been constant. The majority of the cultures have fallen into the group of cocei. Streptococei have predoninated but staphriococei have been quite common. The streptorocei most often found associated with the genital organs of cattle and fetuses are those which belong to the viridans group. The majority of these have been shortchained and composed of rather large, distinctly oval segments. 
In many cases only pairs were observed but this was probably due to the medium and to the length of time the culture was grown after isolation. Quite a large number of hemolytic streptococei belonging to the Beta type have been recovered, as well as a few strains belonging to the group that Brown (37) calls "alpha prime." In the latter case inmediately surrounding the colony is a narrow zone of corpuscles that have not become hemolyzed, while surrounding this zone is a broader one in which hemolysis of the corpuscles has taken place. The various results of the inoculations of these streptococei from the genital canal made upon the sugar media have not yielded anything definite as yet. There seem to be many slight variations in each strain which make anything like classification at present difficult.

The staphylocoeci have been mainly staphylorocens albus and Staphylococcus aureus. Some of them have been hemolytic and some non-hemolytic. A larger percentage of the culures of staphylococeus aureus has heen hemolytic than of Staphylococcus albus.

Bacterium abortum was recovered from many of the different genital organs. Before definitely designating an organism Bucterium abortum, I have injected it into guinea pigs to see if it produced the characteristic lesions, and have made antigens from the cultures and checked them against positive abortion serum. The other biological and staining characteristics have also been carefully worked out.

A few Gram positive spore-bearing rods and Gram negative rods which rould not be identified were isolated at various times. especially from the cervix and anterior part of the vagina, as recorded on the charts. Oecasionally organisms from the colon-aerogenes group, paracolon types, Ps. pyocyaneus and $B$. pyogenes have been recovered but their cultural rharacters are too well known to need description.

\section{EXPERIMENTAL}

In connection with this investigation, experimental work has been carried on with calves of various ages and with a limited number of heifers. The purpose of these experiments has been to find: First, what the eflect of some of these organisms would be upon the reproductive organs of young animals if bacteria were injected directly into the uterine cavity; second, whether the genital canal could free itself of infection when bacteria were injected directly into the uterine cavity, and, if it could do this, how long it would take for the microorganisms to disappear; third, whether these bacteria had any affinity for, or would localize in, the genital canal, if suspensions of the organisms were injected intravenously.

In case of the males the different suspensions of hacteria were injected into the scrotal sac or testicular tissue with a hypodernic syringe. The uteri of the females were exposed through the flank after laparotomy had been perforned, and the bacterial sumpensions injected with a hypodermic syringe directly into the uterine cavity. As a rule the udders of the calves were injected with the same organism which was placed in the uteri. Intravenous injections were made in the ustual manner.

Very heary bacterial suspensions of Bacterium abortum were used, about twice as cloudy as a bouillon culture of $B$. tifphosus. Four different strains of the Bang organism were used, two from the $\mathrm{C}$. S. Bureau of Animal Industry and two isolated from aborted fetuses in om own laboratory. The cultures were grown on nutrient agar slants, washed off with sterile saline solution, and mixed before injection. The streptococei which were used were isolated from the genital tracts of sterile cows showing extensive lesions, such as adhesions of the different parts. These saline suspensions were not so heary as those made from Bacterium abortum. B. proteus vulgaris, which had been isolated from a case of pyometra in a hitch. was injected into the udder and uterine cavity of Experimental Calf 15.

After various periods of time, the animals were slaughtered and the genital tracts of the females were removed and cultured as described under technic. 'The testes, epididymes and seminal vesicles of the males were cultured after removal in the following manner. A string was tied tightly around the neck 
of the serotum and the latter was severed between the string and the abdominal wall before the abdominal cavity was opened. The testes and epididymes were removed after an incision was made in the abdominal wall on the median line and the symphysis pubis severed. The mass of fat at the neck of the bladder which usually surrounds the seminal vesicle was cut away with sterile forceps and knives and the vesicles removed with it. These were placed in sterile towels, taken to the laboratory and cultured in the same manner : similar tissues.

Thirty-three animals were used in this expeximental work (See Chart MII), 12 males and 21 fenales. They were kept in isolated stalls with tight partitions, clean straw being used for bedding. Most of the calves had nothing but whole milk fed to them from individual pails. One or two older animals had some liay and grain.

The scrotal sites of 3 males were injected with 1 c.e. of a living culture of Bacterium aborlum and two with a live suspeusion of a streptococcus viriclans. These were slaughtered in from 17 to 73 days. A streptococus was the only organism recovered and this was found only in an atrophied testicle of one of the calves. Six more males were injected intravenonsly witi: 10 c.e. of the Bacterium abortum suspension, many of the animals receiving the injection twelve times, making a total amount of 120 c.c. In none of these cases was Bacterium abortum recovered from the testes, epididymes or seminal vesicles. In one case (23) a 10 c.c. injection of a streptococcus was made following an injection of the Bang bacillus per vein but the eultures from this tract were also negative. These six animals were slaughtered in from 3 to 48 days after the first injection.

One female calf received an injection of 1 c.c. of a suspension of Lacterium aborlum in her udder. She was slaughtered 51 days after injection but cultures from her genital tract and udder were negative with the exception of one colony of Staphylococcus albus from one ovary. The uteri and udders of four other females were injected with five c.e. and 3 c.e. respectively of a suspension of Bacterium abortum. The abortion organism was recovered from the uterus and vagina of Calf 7 of this group, after having been inoculated 15 days, and also from the uterus of Calf 13 which was slaughtered after having been inoculated 65 day:. The organism was not recovered from the other two females although an organism from the colon-aerogenes group was recovered from the uterus and udder of Experimental Calf 14 and Ps. pyocyaneus from her vaginal mucus. 'The udders of all these females were negative. The uterus of Experimental Calf $S$ was injected with a culture of Streptococeus viridans isolated from Fetus 32. Twenty-five days later the organism was not recovered. Experimental Calf 10 received 5 c.c. in the nterus and 3 c.e. in the udder, of a culture of streptococeus isolated from the genital tract of a sterile cow that had endometritis, salpingitis and ovaritis. Sixteen days later the calf was in excellent health and was slaughtered for veal. An examination of the genital tract slowed that the uterine apices, ovaries and oviducts were all adherent in a mass of fat. The pavilions were adherent to the ovaries, in fact the lesions were very similar to those that have been found in the sterile animals which we have examined. A streptococeus with identical characteristics of the organism injected was recovered in pure culture from the adhesions and from the mucus in the vagina.

Two other females, 31 and 32, were injected intravenously with cultures from Streptococus ziriduns isolated from the genital trast of a rom suffuring from hydrosalpinx and cystic ovaritis. Each received three injections, one of 5 c.e. and two of $10 \mathrm{c} c$, of the suspension over a period of eiglit days. Calf 32 developed a severe arthritis in the left stifle joint from which she did not recover. The ealves were slaughtered in 73 dars after the first. injection but there was no opportunity to culture the affected joint. The cultures from the genital tracts were negative.

Five females were iniected intravenously with 10 c.e. of Bacterium abortum, several receiving this injection 13 different times. Bacterium abortum was not reovered from the genital tract or udder of an of this group of animals. 
One small female calf (30), expelled prematurely at eight months, was injected intravenously with 10 c.e. of a suspension of Bactcriam abortum. The calf died the following day and Bacterium aboitum was isolated from her uterus. The cultures from the heart's blood and spleen were negative. The dam of this calf had retained placenta but Bactcrium abortum was not recovered from it, although her serum agglutinated an antigen made from the organism.

The uterus and udder of Experimental Calf 15 were injected with a culture of $B$. proteus vulgaris, 4 c.c. in the uterus and 2 c.c. in the udder. The organism had been recovered from the uterus of a bitch suffering from pyometra. The calf was slaughtered 37 days later and the organism not recovered, but a staphylococcus was isolated from the uterus.

Two female calves were kept as checks under the same conditions as the calves that were injected. The cultures from their genital tracts were negative. Three animals are still living, experimental Calf 11 , aged 16 months, 12, aged 17 months, and 18 , aged 6 months. Observations are being continued on these animals. The uterus of number 11 was injected with 5 c.c. of a culture of Streptococcus viridans isolated from the genital tract of a sterile cow and the same amount was injected into her udder. At present she is in good condition and comes in estrum regularly. Number 12 received 10 c.c. of a live suspension of Bacterium abortum in her uterine cavity and 5 c.c. of the same suspension in her udder. She is now pregnant $4 \frac{1}{3}$ months and in good condition. Calf is received intravenously 10 c.c. of a live culture of Bncterium abortum five times. 'The injections began when she was 20 days old and were continued over a period of one month. She is at the present time apparently in excellent health.

Bactcrium abortum was not recovered from the genital tracts of the male or female calves that received injections of this organism intravenously, with the exception of Calf 30 as mentioned. It was recovered from the spleens of all the calves with the exception of Calf 23 which died the das following the injection, and Calf 24 which was slaughtered the day after injection. Tn one case Bacterium abortum was isolated from the mediastina] lymph glands and also from the two lymph glands removed from the pelvic: cavity. Undoubtedly it would have been recovered from lymph glands in other cases had cultures been taken. In several cases Bing's bacillus was recovered from the lumgs also.

The spleens of many of the calves from which Bactorium abortum was recovered were enlarged. in one or two eass being twice as large as normal. The splenic pulp was increased in amount and much darker in color than it should have been and the corpuscles enlarged. In other cases the spleen was very friable. These conditions are very similar to those observed in the spleens of guinea pigs a short time after they have heen injected (10 to 14 (lays). Apparently this organism has an affinity for the same tissues in the calf as in the guinea pig. Although abscessation of the tissues, such as the liver, epirlidymes, lungs, etc.. was not produced, it might be done if nroportionately the same amount of injected material should be given the calf as the guinea pig. The atrophying of the testicle, as seen in guinea ligs, was not observed in any of the calves injected with Bacterium abortum.

Although in cases where Bacterium abortum or the other organism injected was not isolated from the genital organs at time of slaughter. staphylesocer, streptococci and other miscellaneous organisms were sometimes recovered. Intra-uterine and intravenous injections secmed to have a detrimental effect upon a majority of the calves, especially the youngest animals. In many cases they showed a temporary diarrhea or came down with pneumonia. The genital tracts from those animals which did. not thrive during the experiments were the ones from which bacteria were recovered as a rule.

The serum of all the animals except those that died or were killed a very short time after injection $(23,24,30)$, agolutinated a Bacterium abortum antigen in dilutions of 1 to 600 . This was the highest dilution made. The method of injection, intravenous, intra-uterine, udder or scrotal sac, seemed to malie no differctice in the reaction. 


\section{DISCUSSION ANI SUMMARY}

To judge from the above work it seems that there is a similarity between the bacteriology of the human female genital tract and that of the female of the bovine species. In the human female there is found the gonococcus, while in cattle Bactorinm abortum has apparently adapted itself peculiarly 16, the pregnant animal. Aside from these differences the bacterial flor: of the reproductive organs of the two species is very much alike. 'The streptococeus is found predominating in "attle and has been isolated from 17t different parts of all the genital tracts examined, the staphylococcus 90 times, Bacterium aborlum 17 times, organisms frum the colom-aerogenes sroup 4 times, Burillus p!yogenes repsulatus ; times, Bacillus pyogenes 3 times, sarcina 3 times, $I^{\prime} s$. pyocyaneus 3 times, fungi 3 times, $B$. paratyphoid $B$ twice, paracolon once, and unidentified rods eight times.

From these data it appears that the genital tracts of rattle should nurmally be free from hacteria. The results ubtained from the younger animals seen to support this ronclusion although microorganisms are sometimes found in their genital orgats. There seems to he a dose relationship between lle presence of bacteria in the genital canals of calves and the various - rmptoms of ralf infections observed, especially enteritic and pneumonia. When a calf has sulfered from surh infertions. especially from enteritis, and has recovered, one can, as a rule, isolate hacteria from the genital canal of that calf if it is slaughtered soon after recovery is made. The type of infection may vary and the amount will vary according to the severity of the disease. If the animal is slaughtered even several months after recovery, there is also a greater possibility of recovering microorganisms in culture from the genital canal than from the tract of a calf or heifer that has not suffered from disease.

The genital tract of a fetus or young calf is almost completely filled with a very viscid, tough, faintly cloudy mucus. The vagina is usually greatly distended with this fluid and remains so for the first four or five weeks after birth. After this time the amount seems to decrease and only the walls of the vagina are covered with it, although after puberty, when the animal romes in estrum, a large amount of this mucus is secreted. Endouhtedly this has no other than a mechanical action for cleansing the vagina. The mucus of entrum differs from the mueus found in the genital canal at birth, the former being very clear and transparent. The latter has been collected with sterile pipettes from the vaginae of calves, placed in ritro, and tested for sterility. Streptococei and other organisms have been placed in the mucus and left for 48 hours after which time cultures were again made. I have not failed to recover the organism which I had placed in the mucus. Further, if the mucus and organisms were incubated for 24 hours, heavy growths of the organisms were found in many eases when smears from the mucus were made. The reaction of the mueus in the genital canal of the fetus. when tested with litmus paper, is distinetly alkaline or neutral. It cannot have, therefore, a very marked bactericidal action.

Observations have been made as regards the matting of the hairs of the vulvar tufts of these calves, all the animals having been kept under the same conditions. It has been found that when the hairs are clean and free from fecal mattcr, pus and mucus, cultures from the mucus in the anterior part of the vagina are prutically always negative, while eultures made from the vaginae of calves with vulvar hairs soiled with excretions and secretions, practically always yield bacteria. This factor seems to be a safe criterion for differentiating a vagina free from bacteria from one containing microorganisms in young females, and no doubt bears some relation to the bacterial content of the reproductive organs of adult animals. In the immature animal it has been found that if the anterior part of the vagina is infected with different microorganisms, the uterus also will contain bacteria.

The genital tract of an adult cow with a normal breeding history is comparatively free from bacteria, especially the ovaries and oviducts, cervix and external os. In the case of distinctly diseased genital organs, the majority 
cf the microorganisms were isolated from the uterine adnexa. Approximately the same number of bacteria were recovered from the diseased uterus as from the uterus of the normal individual. As a rule, the uteri of the diseased tracts had been douched with various antiseptic solutions or treated in other ways, and this possibly had an influence upon the bacteria in this organ, keeping the number as low as or even lower than in normal cases (See graphs). Generally only a few colonies, or possibly a meagre growth, have been noted on most of the cultures. This is especially true of the streptococeus which has been recovered so many times, and may be due to the artificial medium upon which the bacteria are grown.

Since the majority of the cultures from the genital tracts of the pregnant uteri, as well as most of the cultures from the fetuses removed from the latter, were negative, it is difficult to say whether there is a definite relation between the bacterial flora of the uterus and that of the tissues of the fetus. In one case, that of Tract 11, which was distinetly abnormal, the same bacteria were isolated from the fetal fluids as were recovered from the ovaries and oviducts of the dam.

In comparing the hacteriology of aborted fetuses with that of fetuses removed from pregnant uteri, there is found a much larger number of bacteria associated with the tissues of the former. It seems strange to find, in checking up the cultures, that streptocoeci have not been found in conjunction with Bacterium abortum; Staphylococcus albus and aureus have been associated with the latter many times. Fetus 32 gave pure cultures of a Streptococcus viridans directly from the tissues, but when extracts of these tissues were ground up and injected into guinea pigs, Bacterium abortum was recovered from the tissues of the latter. The distribution of the bacteria in the fetus is remarkable. In some cases cultures of an organism can be recovered only from the stomach contents, intestinal tracts and possibly the lungs, while in other ases they are recovered only from the heart's blood, spleen, liver, etc. At times bacteria are recovered from all the tissues. It seems that the sources of infection must be different in such cases. Evidently, when the infection is in the stomach contents, intestinal tracts or lungs, it must have entered the mouth of the fetus and have been taken in with the fetal fluids which are being swallowed continually. Where it is found only in the heart's blond, spleen, etc.. it must have come directly into the hlond stream from the eotyledon which may have been infected to such an extent that the epithelium has been damaged and the bacteria carried into the fetal circulation. When the epithelium of the intestine is damaged from toxins or other agents that are capable of destroying the mucous membrane. bacteria gain entrance into the circulation, as for example, the Bacillus typhosus in typhoid fever.

According to the data that MeFadyean and Stockman (38) submit in their work on Episootic Abortion, they have not found Bacterium abortum in the circulation of the fetus unless it was first present in the intestinal tract. showing that the infection was taken into the circulation from the intestinal tract. In several cases I have recovered bacteria from the fetal circulation and have been unable to get growths from the intestinal tract. The original source of the fetal fluids must be the blood stream, but there is apparently some difference of opinion as to what tissues excrete or secrete them. They may have two sources or more. The entrance of infection into the fetal fluids also seems to be in doubt. The amniotic fluid which is secreted by the ectoderm of the amnion is the only fluid that the fetus can take into its digestive tract. Therefore, infection must be present at the time of conception or within three or four days from that time if it gains access to the amniotic fluid. The only other possible source of infection of the amniotic fluid is the blood supply of the amnion. The kidney of the fetus secretes the allantoic fluid which becomes enormous in amount in the latter period of pregnancy but this does not communicate with the amniotic fluid. Do the bacteria come from the blood through whatever channel the fetal fluids pass, or are they present in the uterine wall or cavity before conception, having been carried there by the blood some time previous? Hagan (39) 
suggests that the infection comes from the uteru-chorionie space and is absorbed or grows into the fetal fluids through the necrotic tip of the chorion which is so common a condition in cattle. When infection is found in the genital tract of the fetus it must have been carried there by the circulatory system. It cannot be stated whether there are certain bacteria which have a special preference for the genital canal, or whether these bacteria become deposited there accidentally through some special arrangement of the tissues, and find the tract a favolable place in which to remain dormant or to multiply.

The source of infection in the genital canal of adult animals presents more difficulties than it does in the fetus or immature animal, where, with perhaps the exception of the posterior part of the vagina, the external source can be eliminated. The two chief reasons for this are the absence of coitus in the young and the mechanical obstruction which the tough mucus of the immature tract must afford to bacteria. Althomgh microorganisms have been isolated from only a few of the genital tracts of fetuses, calves and virgin heifers, a comparatively small number of such animals have been worked upon. It seems evident that a certain percentage carry infection in their genital canals from calfhood to puberty and that this infection is borne there either by the blood or lymph stream. Probably there are certain individuals that are able to eliminate this infection after it is once established. There is also undoubtedly a group of adults that incur the infection during pregnancy or afterwards, in fact it is not impossible for the organism to enter the reproductive organs at any time. Rosenow has shown that certain streptococei, especially the viridans group isolated from various sources, such as endocarditis, arthritis, duodenal nlcers, and ovaritis, have an affinity for these same tissues when they are injected into experimental animals. Detwiler and Maitland $(40)$ found that these organisms produced the most lesions in the heart and joints regardless of the site of origin of the culture.

There is strong evidence to prove that the streptococci which have been isolated from non-breeders whose genital tracts show lesions, are the cause of these lesions. Rosenow and Davis (4l) also have isolated Strentocorens viridans from a large number of ovaries of women and have produced oraritis in experimental animals. They report a case of a young girl who had a chronic tubo-ovarian inflammation and also a congenital stenosis of the cervix and uterus. They isolated a Streptococcus vividans from this case. Weiner (42) also reports a case of an 18 year old girl with an ovarian abscess and a comnlete stenosis of either the cervix or vagina. He cultivated a hemolytic streptococcus from the abscess. In surh rases as the last two quoted the source must be hematogenic since infection by extension is eliminated. The case of Experimental Calf 10, which I have mentioned before as receiving an intra-uterine injection of streptococcus viridans, followed by the characteristic lesions associated with this group of bacteria. supports the pathogenesis of the streptococeus.

In a recent paper on Salpingitis (43), we have shown the relation of the streptorocei to the tubes. They were isolated in manj cases of hydrosalpinx and other types of salpingitis. In several instances oviducts, apparently normal macroscopicalls, showed a catarrhal inflammation or a chronic productive inflammation on section, while streptocneci were recovered from the lumen.

In the case of several small aborted fetuses (30 to 45 davs) and in one case of impending abortion (Pregnant Uterus 11). Sitreptococcus hemolyticus and Streptococcus viridans were recovered. It does not seem possible that these organisms can invade the embrvonic or fetal tissue withont cancing some damage. It mar be that the streptococeus iniures the endometrium to such an extent that the embrio cannot remain attacher to the mucous membrane. If such is the case. and I have resovered strentorncei from the uterine wall of manv cases of endometritis' where the mucous membrane has hecome entirely denuder. there is no doubt that many enws which are considered sterile are expelling embross that are nnohserved. hecalse the 
latter cannot become implanted in the inucosa of the uterus after fertilization has taken place and they have descended the tube. It seems very probable that streptococei which are associated with the genital tracts of cows are pathogenic and distinctly so. In the past they have been regarded by many as saprophytes, especially the viridans group, but it seems that this predominating group of organisms in the genitai canal will have to be considered more seriously if the diseases of the reproductive organs are to be controlled.

There appears to be no doubt regarding the pathogenesis of most strains of Bacterium abortum. Much work has been done on natural outbreaks of - ibortion due to this organism, and also experimentally. All of the premature expulsions of fetuses are by no means due to the Bang organism. In the group of aborted fetuses which I have studied, I have found Bacterium abortum in 40 per cent, but if this disease is primarily a disease of the fetal membranes, perhaps a safe percentage basis cannot be established upon the bacteriological findings from the tissues of the fetuses. The placentae have been cultured in many cases and these should be examined in order to eliminate the presence of Bacterium abortum. The recovering of Bacterium abortum in the uteri of aborted fetuses and the udders of two veal calves and one sterile four-year old heifer should be noted. The persistence of Bacterium abortum. in the uterus of a calf sixty-five days after the injection is also interesting. The length of time that this organism remains in a nonpregnant genital tract has been reported to be comparatively short. Most investigators insist upon working with Bacterium abortum and the premature expulsion of the fetus, but the whole problem of the diseases of the reproductive organs is so serious and so complicated that it cannot be solved by studying one organism and one condition. As the work progresses more scientifically and new factors are found, it is very likely that the percentage of abortion due to Bacterinm abortum will become smaller.

The pathogenesis of the staphylococei and other organisms which have been recovered has not been carefully studied. Their virulence may increase at times or the resistance of the animal become so low that they have an opportunity to produce disease, but they probably have little bearing upon the reproductive organs of a healthy individual. When they do cause disease they have just as important a bearing upon that particular case as would Bacterium abortum or streptococcus viridans.

A careful search has been made for the spirillum, or vibrio, which Smith recovered from aborted fetuses and described. I found this organism in large numbers associated with an outbreak of abortion in ewes in 1919 (44), but $\mathrm{I}$ have not recovered it in connection with my work on cattle.

One of the unexpected results of this investigation has heen the comparative failure to isolate members of the colon group. These organisms are so easy of cultivation that, if they had been present, they would have been recovered. Except for cultures that have been isolated from the intestinal tracts of calves and fetuses that lived for only a short time, I have obtained orly five cultures of these organisms and two of these were isolated from vaginae. Judging from the infrequent occurrence of this group of bacteria, it cannot have much weight in the etiology of intra-uterine infections of young calves. In the past much work has been done on the relation of the colon group to the so-called "white scours" and to different forms of ealf pneumonia, but I have found this organism in a verv limited number of cases if the calf was killed and cultured before death from the infection had occurred. It would appear that just before death, or at a time when the cells lining the intestines become injured, the large volume of infection normally found in the intestinal tract breaks through into the circulation. In describing this condition, Zinsser (45) savs: "Thus, as Bail has pointed out, a mass of frogs' eggs will remain entirelv uninvaded while alive, though the water surrounding it may swarm with bacteria of many varieties. but when by some accident such a mass of eggs ceases to live, it immediately falls prey to bacterial infection. The same point is illustrated by the rapidity with which intestinal bacteria will spread throughout the body after 
death, when during life, they have remained confined to the lumen of the intestines, or, at most, get into the portal circulation, to be destroyed in the liver. By the living cell, therefore, an opposition is offered to invasion by bacteria, a rital function which Bail has attempted to make clearer by form:lating it as a law, referring to it as 'Das Gesetz Lebensundurchdringlichkeit.'”

I have tried with many of these colon eultures and by many different methods to produce the same symptoms in calves but have failed in every attempt. Sume hold that this colon group is the cause of many of the calf infections because a serum immunized to different members of the colon. acrogenes group of bacteria apparently has some beneficial effect upon the course of these maladies. In a discussion of this subject, Professor W. A. Hagan of the New York State Veterinary College at Cornell University sugsested that the beneficial effect of this serum may be due to the foreign protein that is introduced and not to the antibodies formed in this preparation. Because of this, normal serum has been prepared from cows, veal calves, and horses. In some cases whole blood has been used and in other cases, defibrinated blood. The results of this work have proven favorable, that is, in herds where the normal serum or blood has been cheeked against the immunized serum, equally as good results have been obtained, and in many cases the calves on normal serum have recovered more quickly and lave been more vigorous than those on immunized serum. Therefore, I fail to see anything specific: in the immunized serum that renders it of more value in treating these conditions than the normal serum.

In three recent outbreaks of these infections in calves, I was unable to i-olate the colon organism if the ealves were killed and cultured a short time before death seemed imminent, or even immediately after death. The contents from the stomachs of the live calves yielded a streptococeus. The meconium and hood cultures and also the placentae from the dams gave this same organism in pure culture. In these herds cultures from ealves that were expelled dead gave an organism identical with that recovered from the living ealves. In many cases I failed entirely to get cultures from the cadaver even though the calf had been dead some time.

There is one type of calf infection that is due apparently to unclean food and insanitary surroundings. This is a form of diarrhea and it can be controlled easily by sanitary methods and by disinfecting the navel cord. The colon-aerogenes group may play a part in this type of infection but I clo not consider it the primary causative agent.

The cause of the intra-uterine iliarrhea is apparently the infection that is present in the uterus and fetus. It is difficult to find the same organisms in a calf that has lived for a time and then died from enteritis or pnenmonia, that have been recovered from its dam. One cannot tell whether the organisms recovered from the dead calf have remained in the tissues since birth or whether they were picked up from some external source. IVith the exception of the instances mentioned above, I have not, as a rule, recovered the same organisms from a ealf that has suffered from septicemia, chteritis or pnemonia that $I$ have isolated from the uteri of pregnant animals, though at no time have I been able to secure for bacteriological examination a megnant animal in a herd that was having heavy losses from these ralf infertions. There does not seem to be enough evidence, except elinical evidence. to prove that the bacteria found in the pregnant uterus are the ctiological factors concerned in the diseases of the young calf after birth.

I am greatly indebted in this investigation to Professor W. L. Williams for his valuable singgestions and for the large amount of material obtained from his department without which much of the work could not have been done. I : am indehterl to Professor D. H. I dall of the Department of Medicine and the ambulatory elinie for supplying me with much material for study. I am also indehted to Professor IV. A. Hagan of the Department of Bacteriology, to Professor J. N. Frost of the Department of Surgery, and to Dr. H. L. filman of the Department of Obstetrics, for generous assistance. 


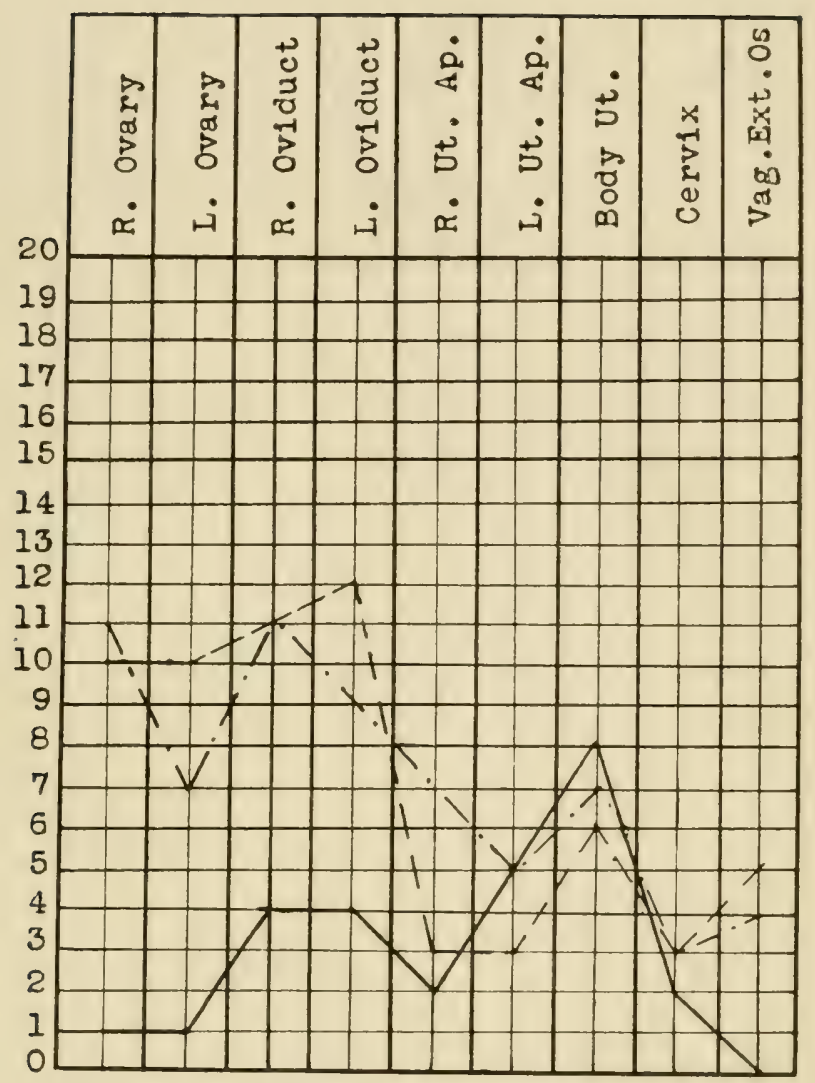

18 normal genital tracts

17 diseased genltal tracts from one herd - - 18 diseased genital tracts from various other herds.-- -

Graph showing distribution of bacteria in genital tracts of 18 normal cows, 17 sterile cows slaughtered in one herd and 18 sterile cows from various other herds. Figures represent the number of times bacteria were isolated from an organ. 



\section{Bibliograpity}

1. Williams, W. L. Cormell Vet. 1919, 9, 204.

2. Report of U. S. Sec'y Agriculture, 1915.

3. Livestock on liarms and Ranches. J.A.V.M.A., 1921, 11, 750.

4. Döderlein. Centralblatt für Gynäk., 1894, 18, 10.

5. Williams. Am. Jour, of the Med. Sci., 1893.

6. Krönig. Centralblatt f. Gynäk., 1894, 18, 3.

7. Winter. Zeit. f. Gynïik., Jss8, XIV, 443.

8. Bensis. Paris Theses. 1899-1900.

9. Bergholm. Archiv, f. Gynäk., 1902, 66, 4!7.

in Walton and Medalia. Surg. Gyn. and Obs., 1912, 15, 682.

Kiister. Kolle und Wassermann, 1912, V1, 458.

Permar. Am. Jour. of Obs., 1917, 75, 652.

Rosenow. J.A.M.A., 1915, LXV, 1687.

Davis, C. H. Surg., Gyn. and Ols., 1916, 23, 540.

Miller. Am. Jour. of Obs., 1916, 74, 450.

Grad. Am. Jour. of Obs., 1918, LXXVIJ.

urtis, A. N. Surge, Gyn. and Obs.. XXVI, 17 S.

weedy, E. H. Surg., Gyn。 and Obs., XXVil, 563.

enzler. Inaugural Dissertation zm Erlangungr der Dokterwürde der hohen Veterinismedizinschen Fakultät der Eniversitit Zürich, 190-i.

iltner and Bandeen. J.A.V.M.A., 1920, LVII, 47.

on Reuss. Krankheiten der Neugeborenen, 1914.

-. ineise. Hegar's Beitrige, 1902.

23. Knapp. Monats. f. Geburts. u. Gynaik, 1897, V.

24. Selimidgall, G. Hegar's Beitrïere, 1913, XiX, 190.

25. Brailowsky-Lounkevitch. Ann. de l'Institut Pasteur, 1915, XXIX, 379.

26. Smith, R. M. Med. Record, Sept. 2, 1916.

27. Hymanson and Hertz. Am. Jour. of Olus., 1917, 75, 66.2.

28. Bang. Jour. Comp. Path. and Therap., 1897, 10, 125.

29. Smith, T. Jour. Exp. Med., 1918, XXV111, 701.

30. Rosenow. J.A.M.A., 1914, LXIII, 903.

31. Smillie, Jour. Exp. Med., 1918, XXVIII, No, J.

32. Liborius. Zeit. f. Hygiene, 1886, I, 115.

33. Nowak. Amm. de l' Inst. Pasteur, 1908, XXII, 541.

Wright, J. Boston Soc. Med. Sci., 1900, V, 114.

Loefler. Nitheilungen aus dem K. Gesundheitsamte, IS94, II.

Huntoon, F. M. Jour. Inf. Dis., 1918, 23, 169.

Brown. Monograph of the Rockefeller Institute for Med. Res., 1919, IX.

38. Meliadyean and Stockman. Fiep. of Com. App. by the Board of Agr. and $\mathrm{Fish}$. to inquire into $\mathrm{Lp}$. Abortion, 1909.

39. Hagan, W. A. Cornell Vet., 1917, 7, 263.

40. Detwiler and Maitland. Jour. Exp. Med., 1918, 27, 37.

41. Rosenow and Davis. J.A.M.A., 1916, LAVI, 1175.

42. Weiner. Surg., Gyn. and Obs., 1918, 27, 622.

Carpenter, Williams and Gilman. J.A.V.M.A., 1921, 12, 173.

Carpenter. Cornell Vet., 1919, IX, 191.

Zinsser. Infection and liesistance, 1914, 5.

\section{FXPLANation OF ChaRts}

Chart I. Pregnant uteri of cows.

Chart II. Normal non-pregnant uteri of cows.

Chart III. Diseased non-pregnant uteri of cows.

Chart IV. Uteri from virgin heifers.

Chart V. Uteri from calves 3-12 weeks old.

Chart VI. Uteri from calves 1-3 weeks old. 
Chart VII. Fetuses removed from pregnant uteri.

Chart VIII. Aborted fetuses.

Chart IX. Aborted fetuses whose dams were injected intravenously with Bact, abortum.

Chart $\mathrm{X}$. Fetuses removed from uteri of cows suffering from dystocia.

Chart X1. Mummified fetuses.

Chart XII. Experimental work.

Blank spaces indicate negative results.

spaces with - - indicate no cultures were made. 


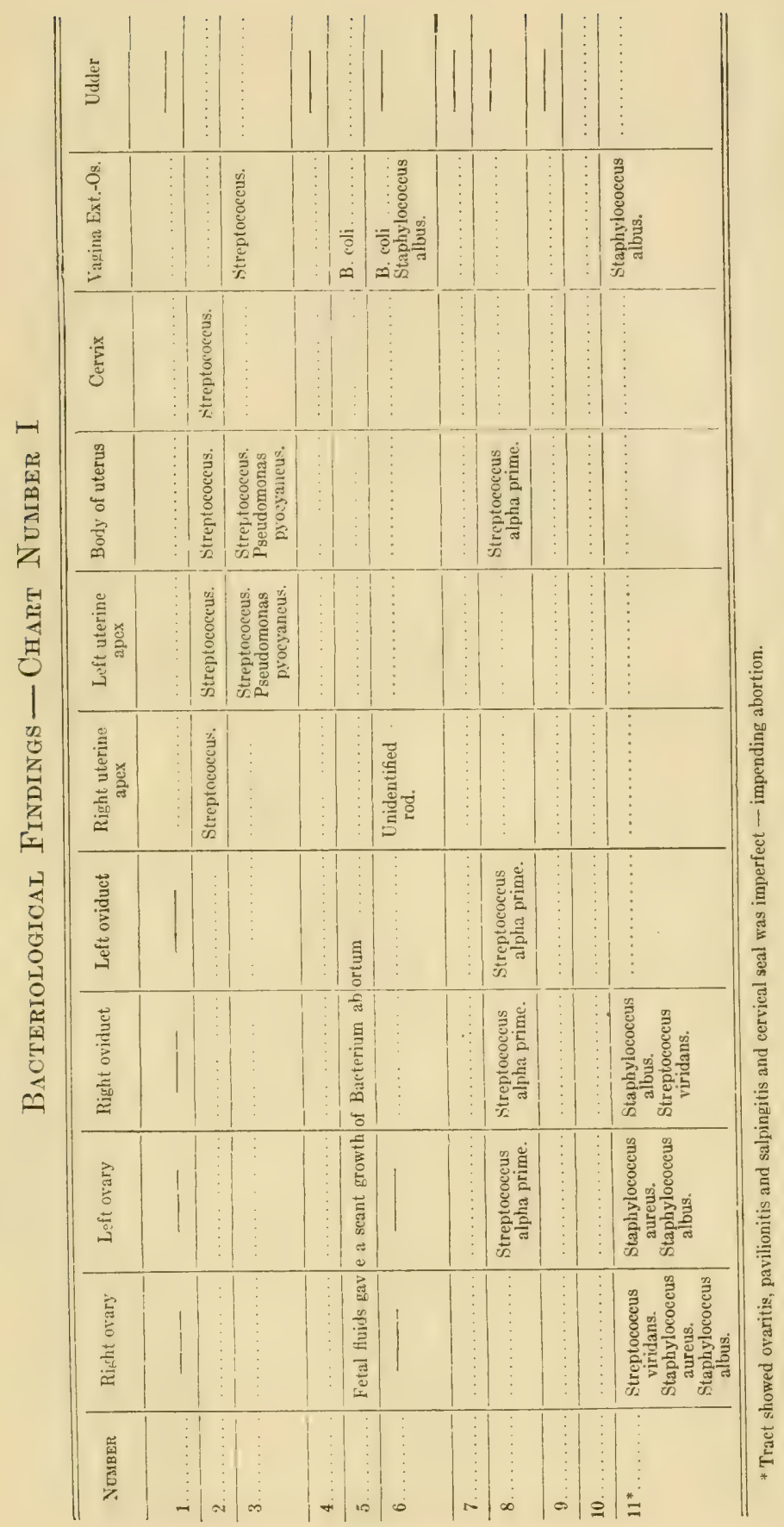




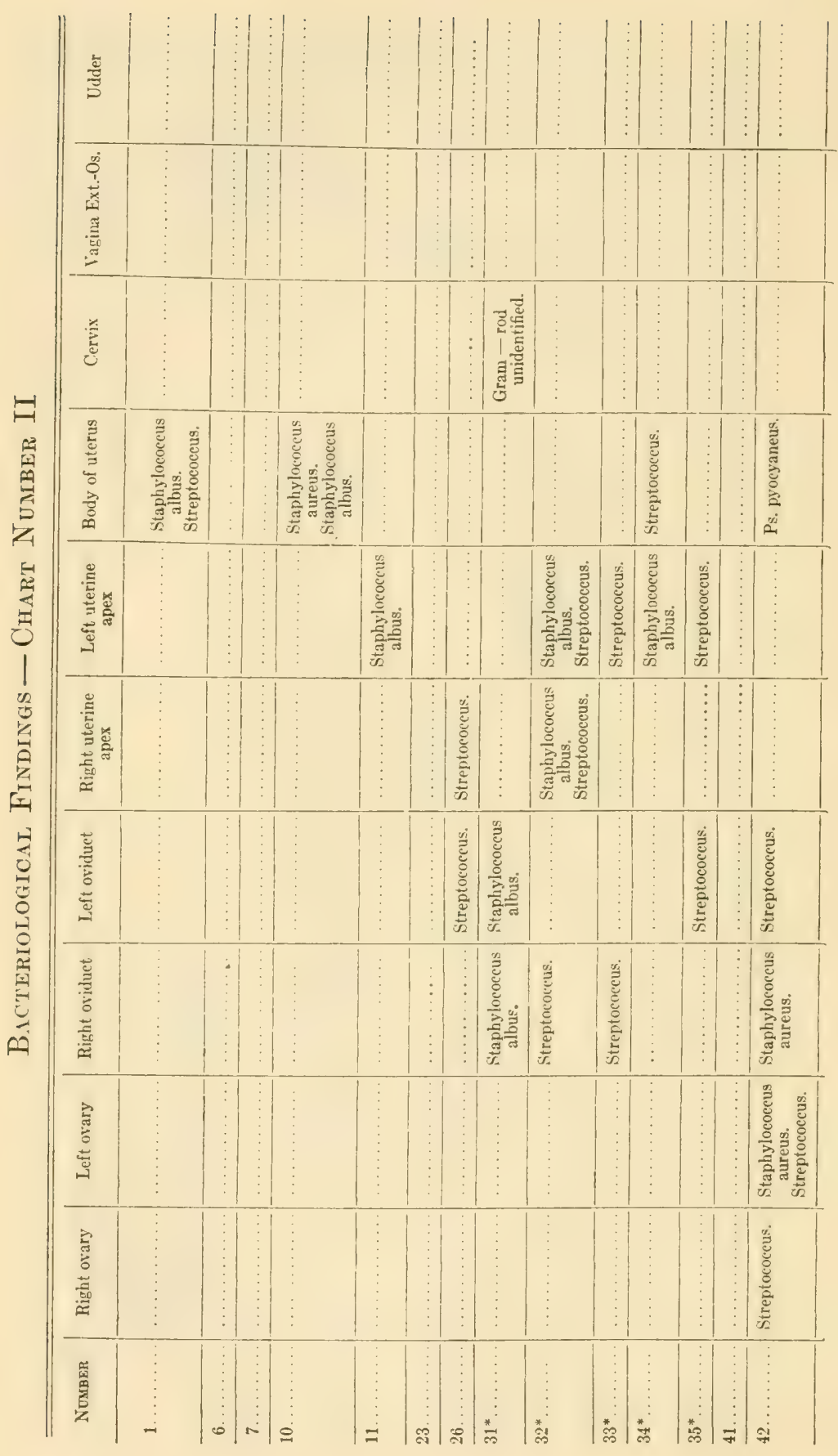




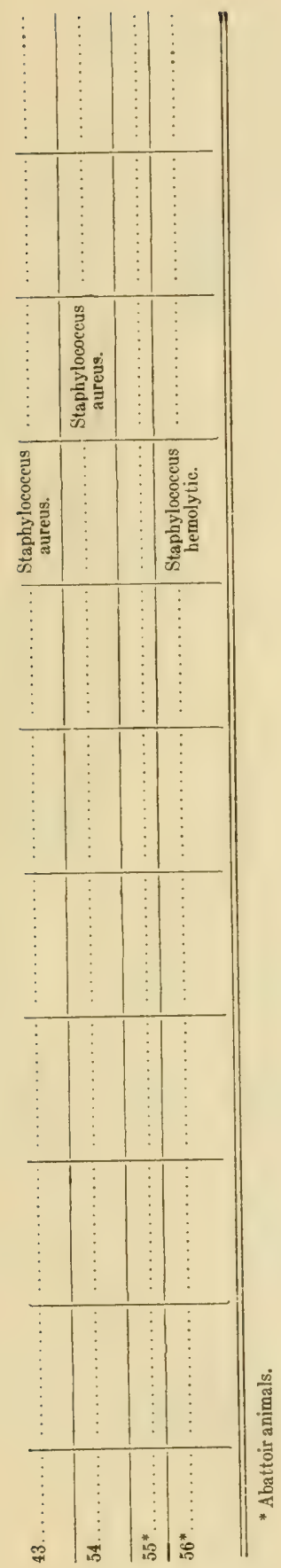




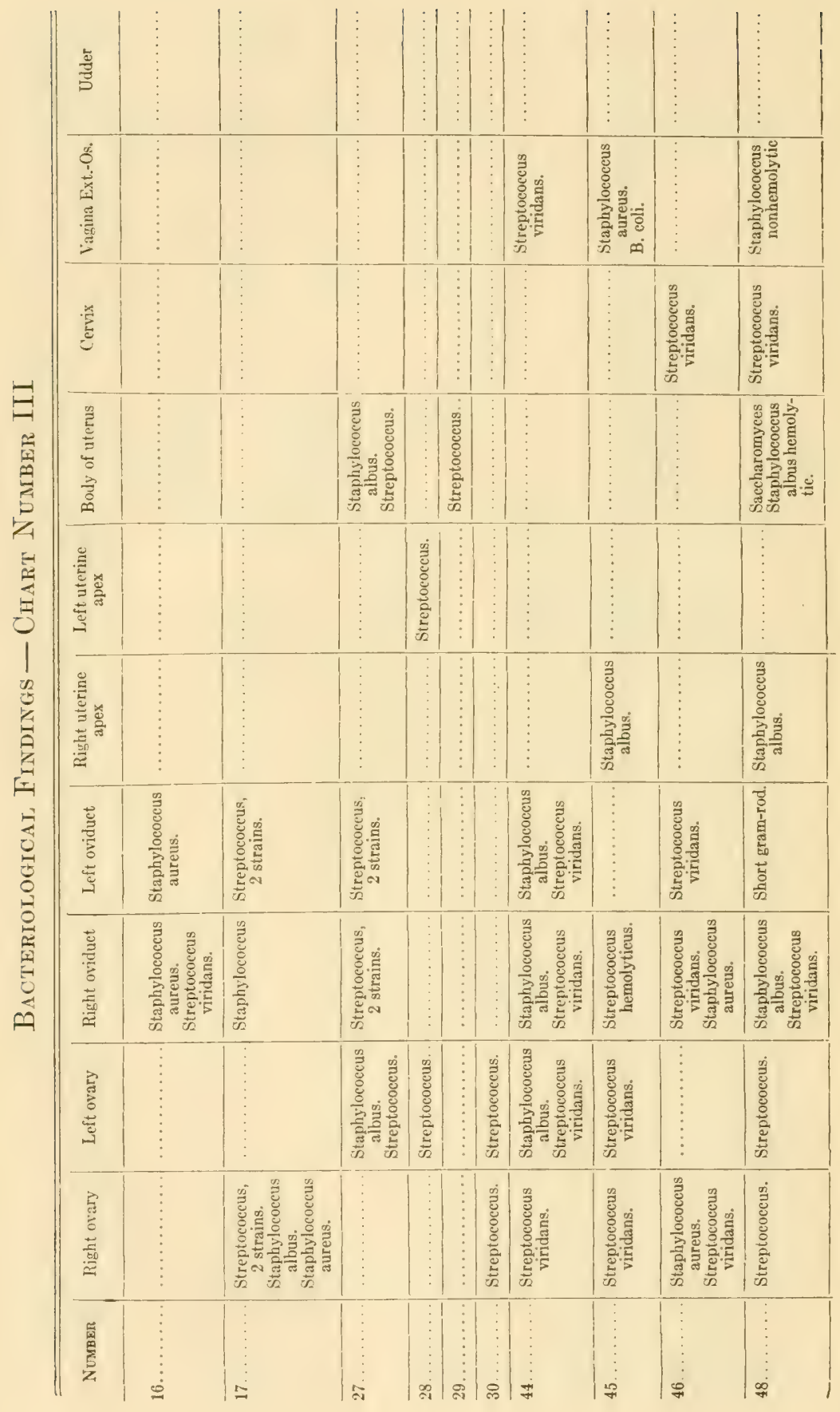




\section{5}

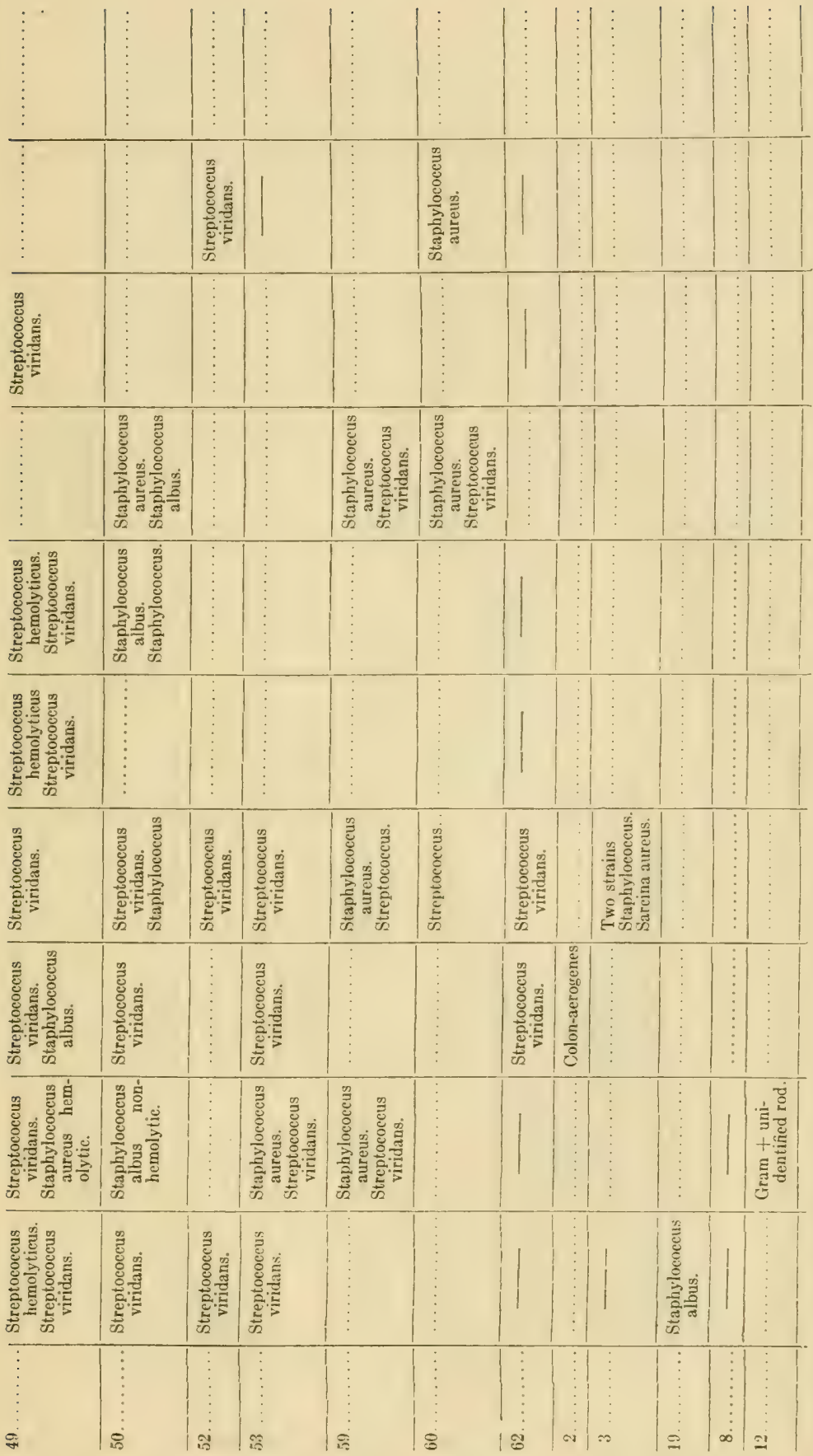




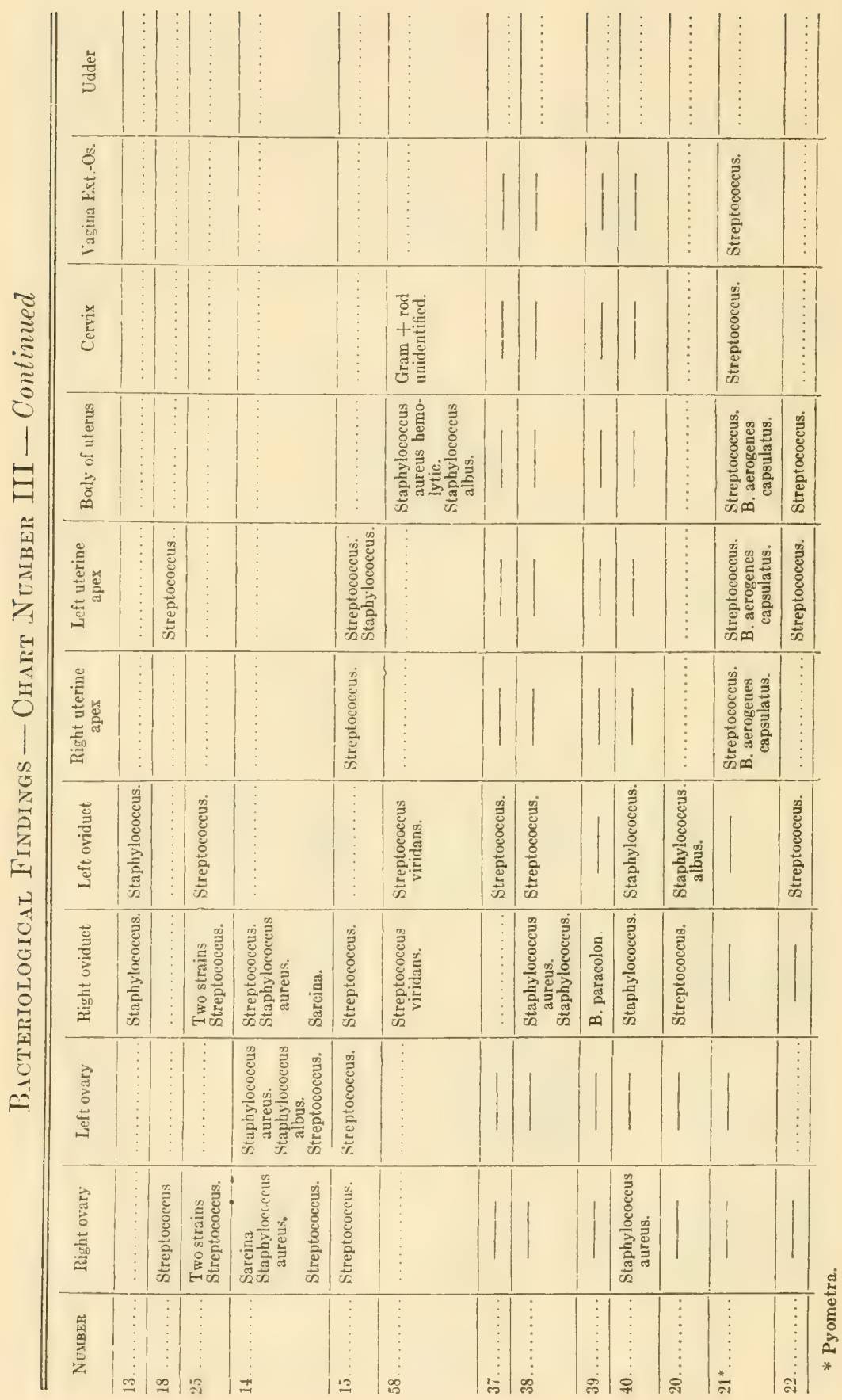




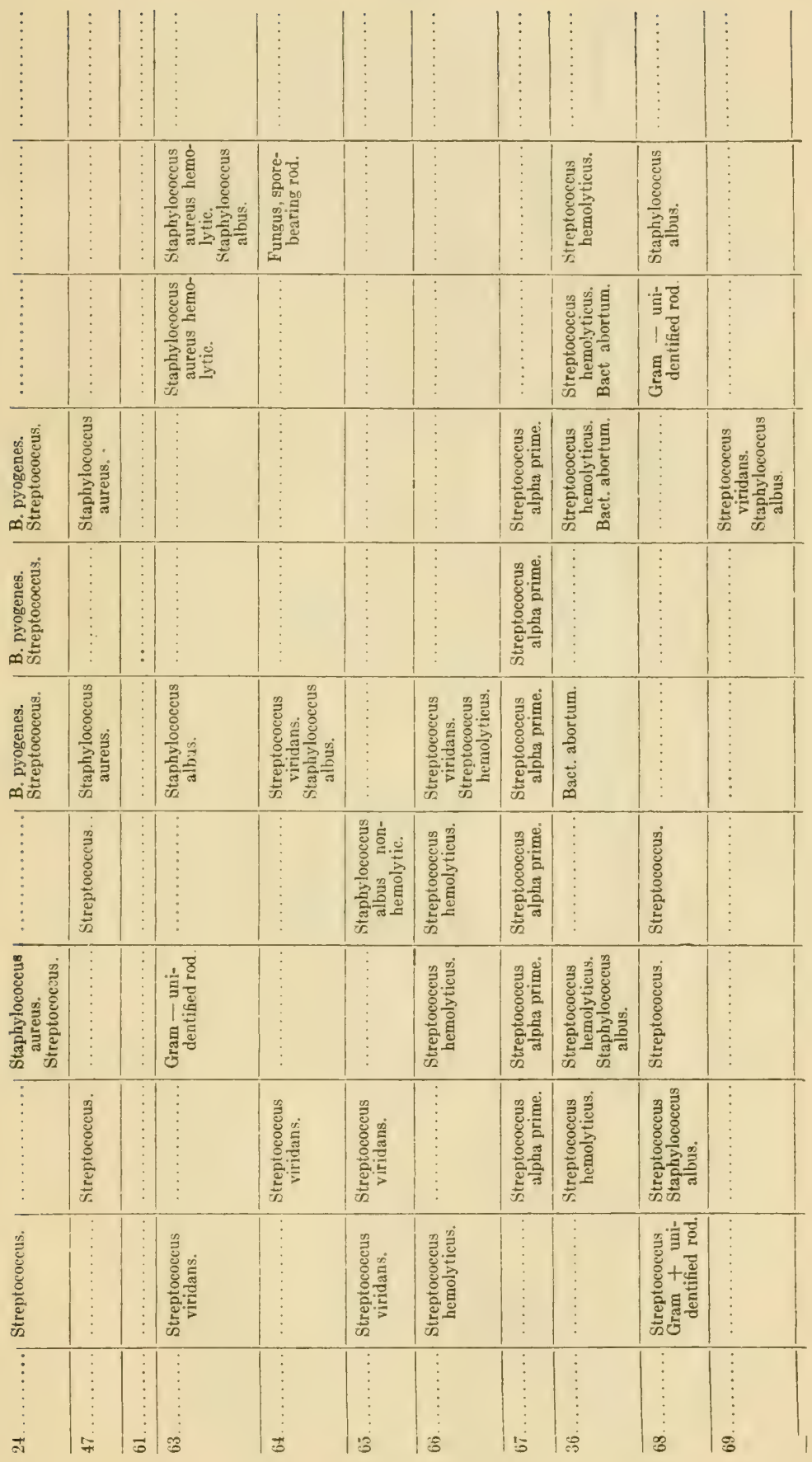


28

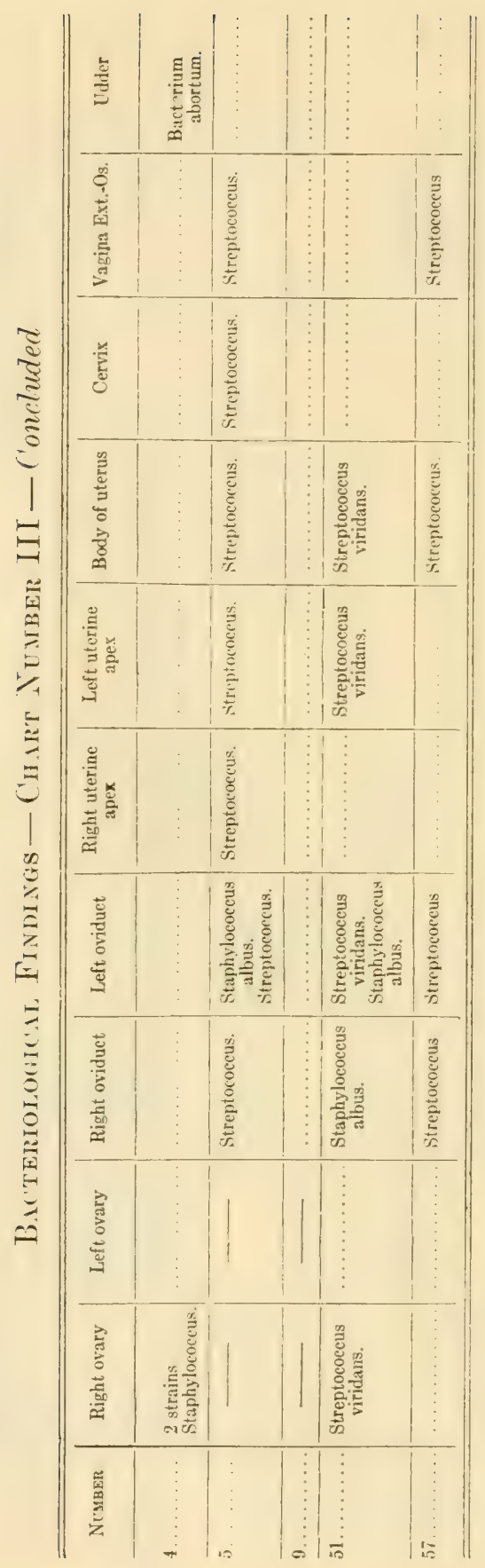




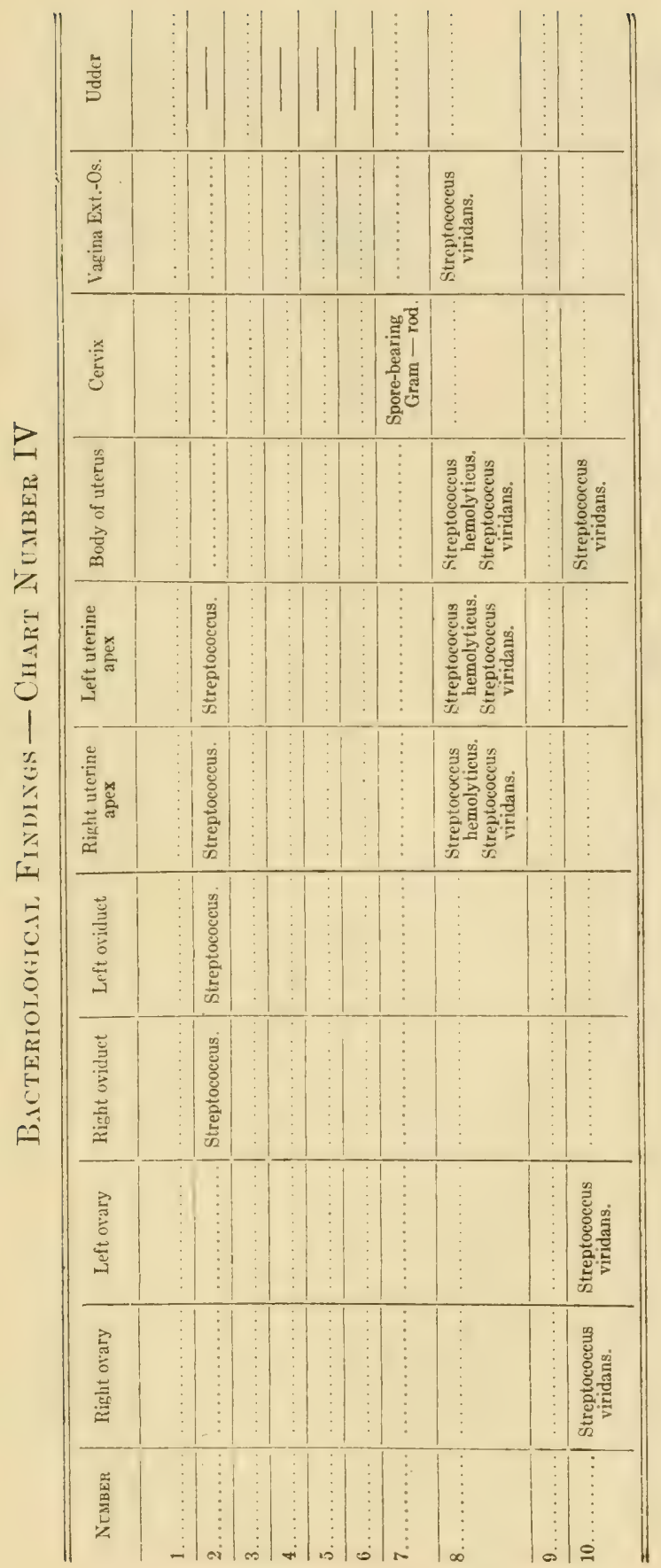




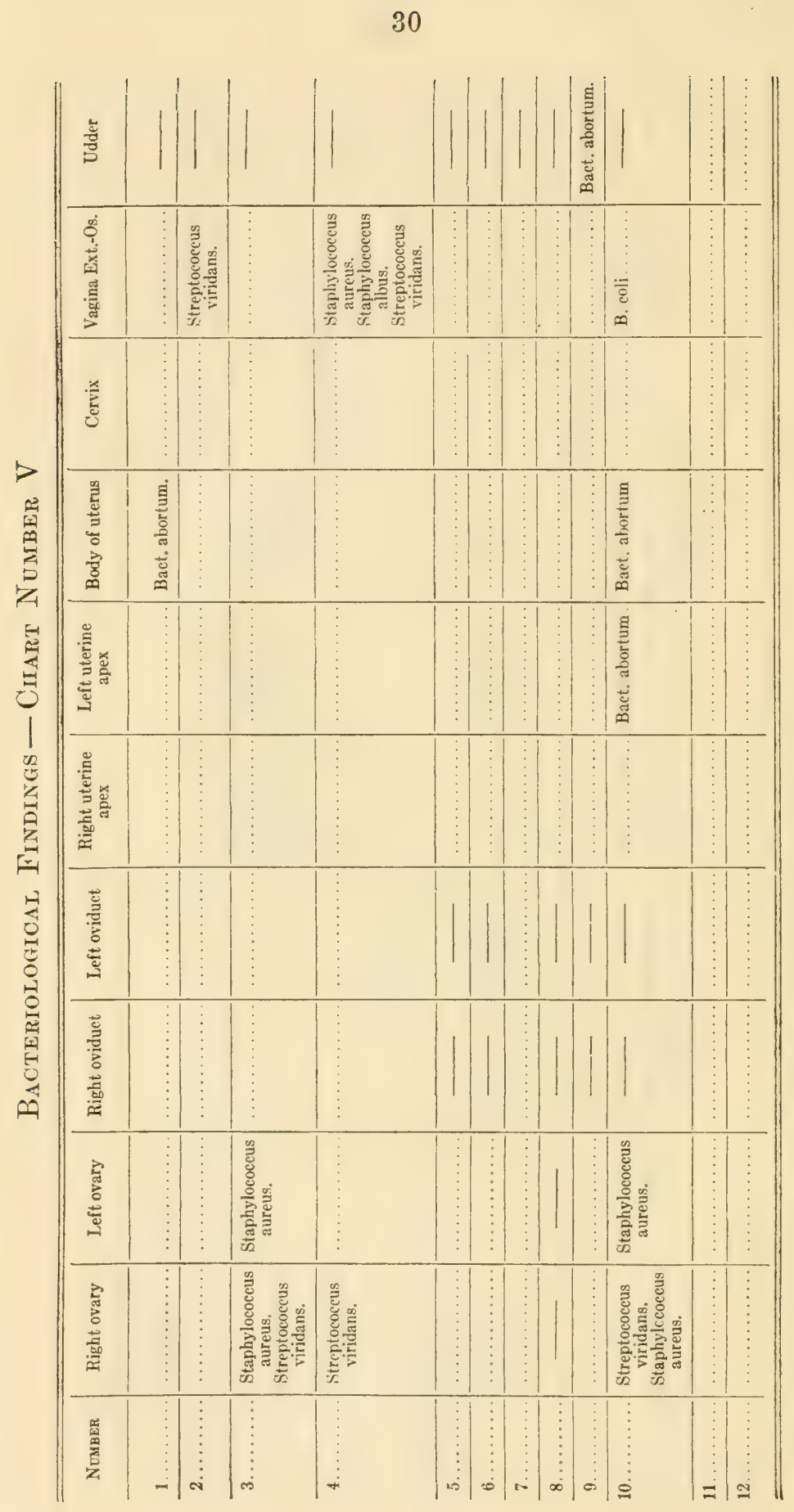




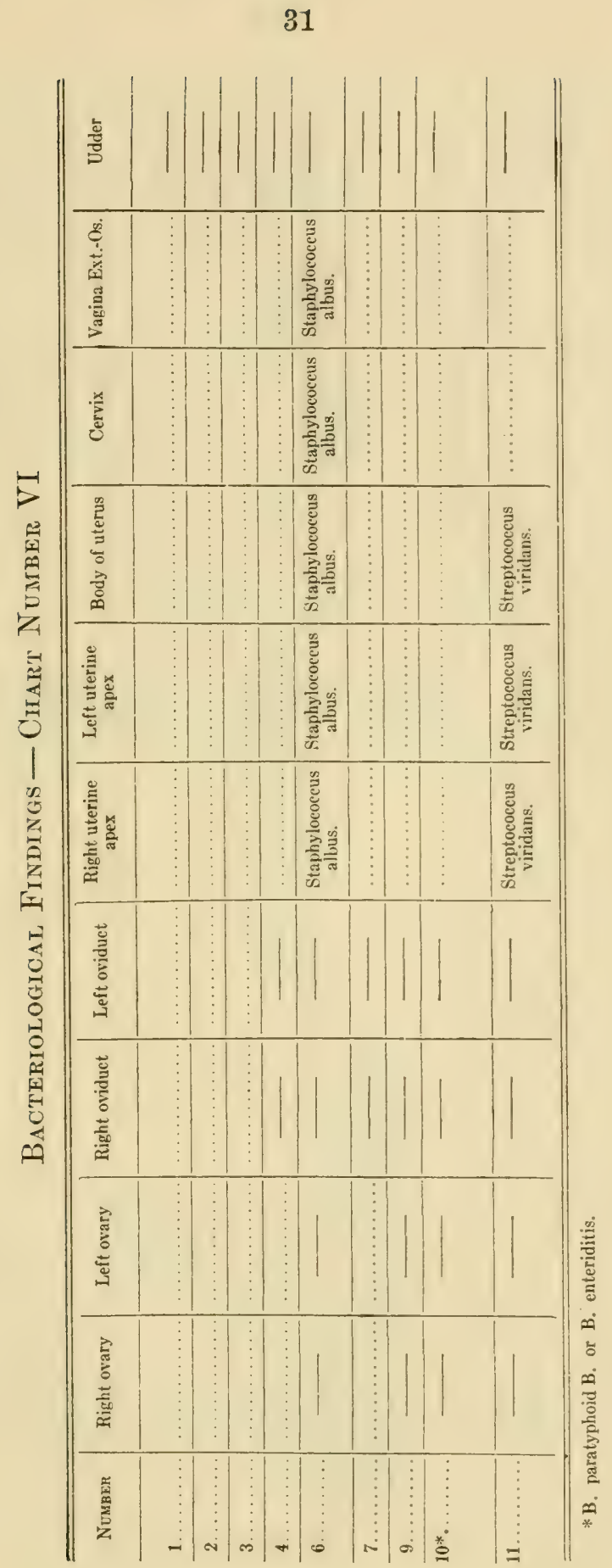




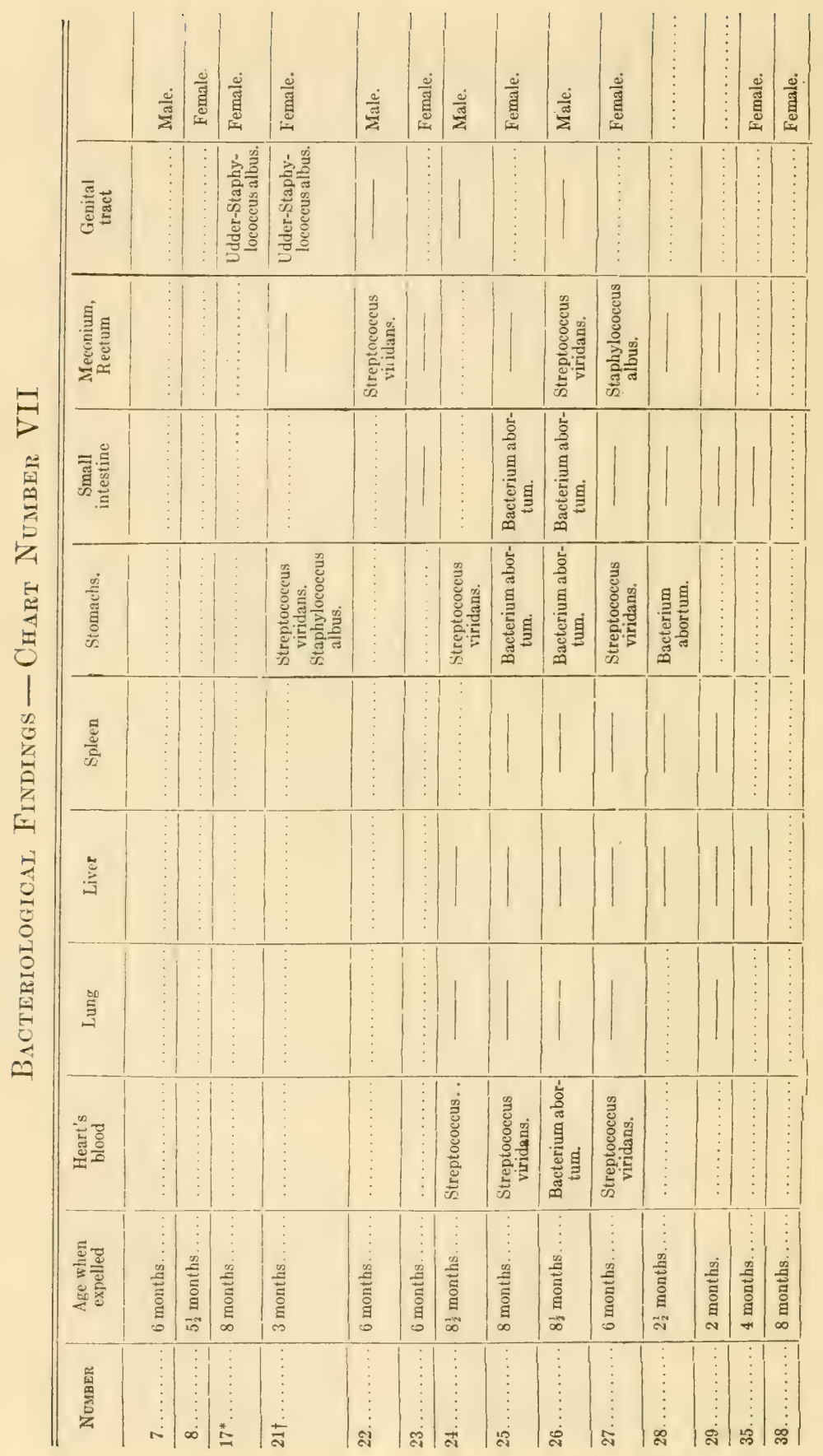



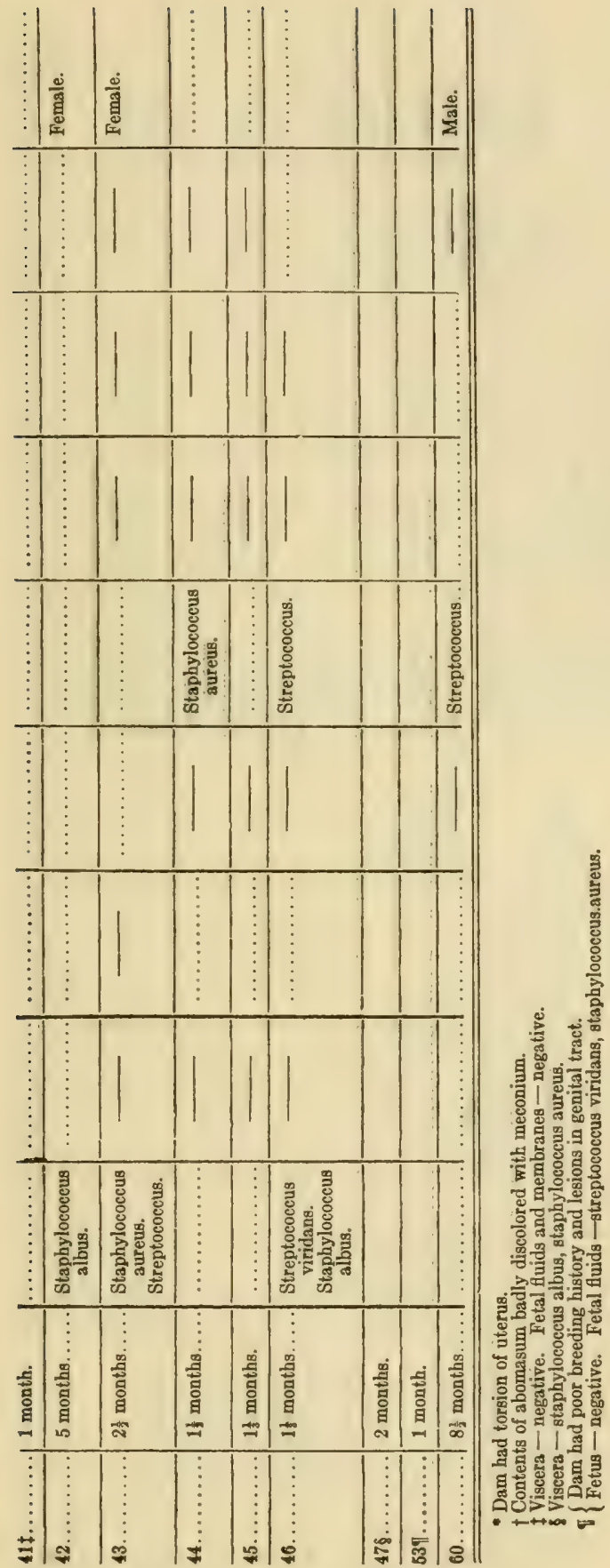


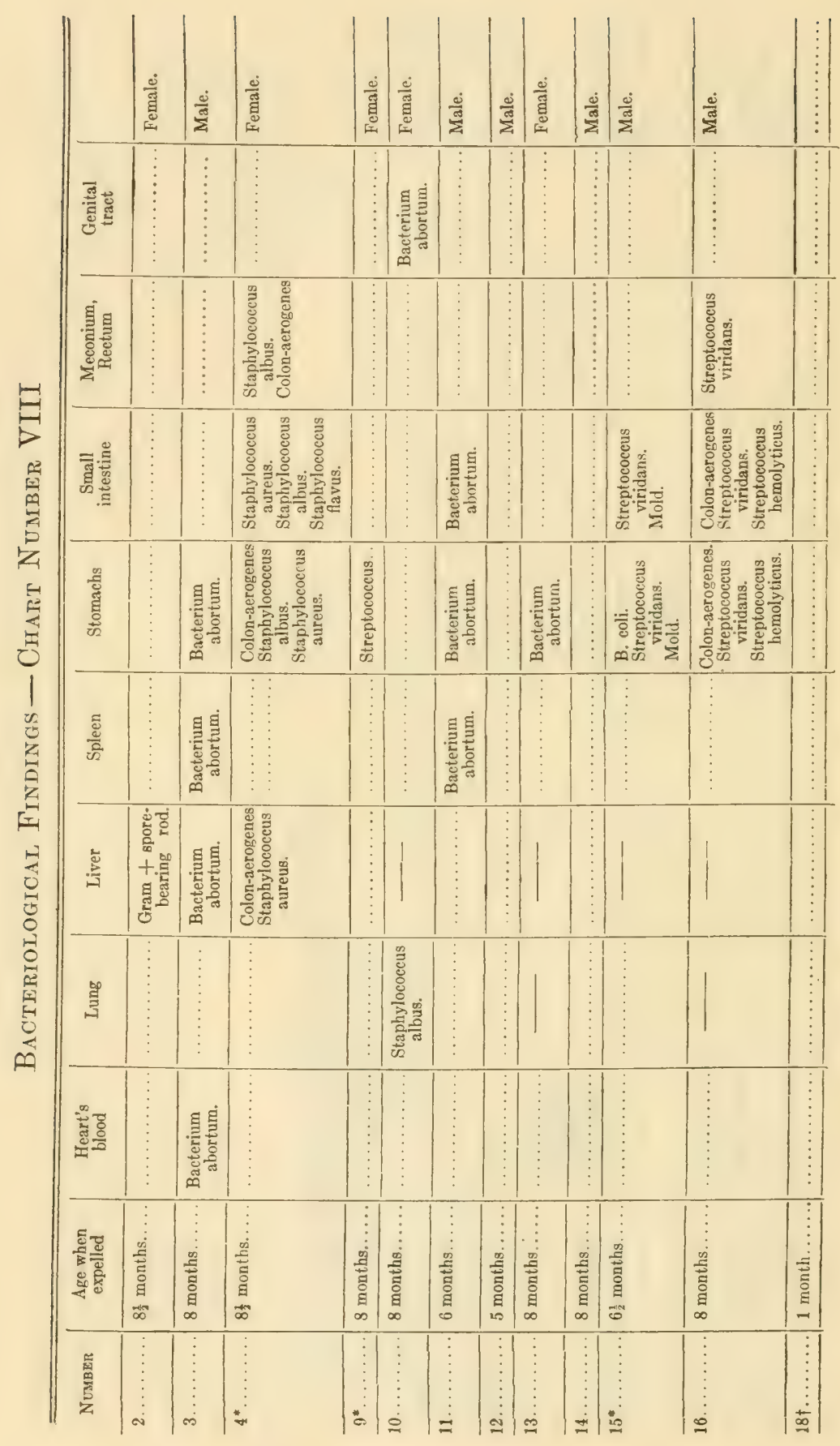




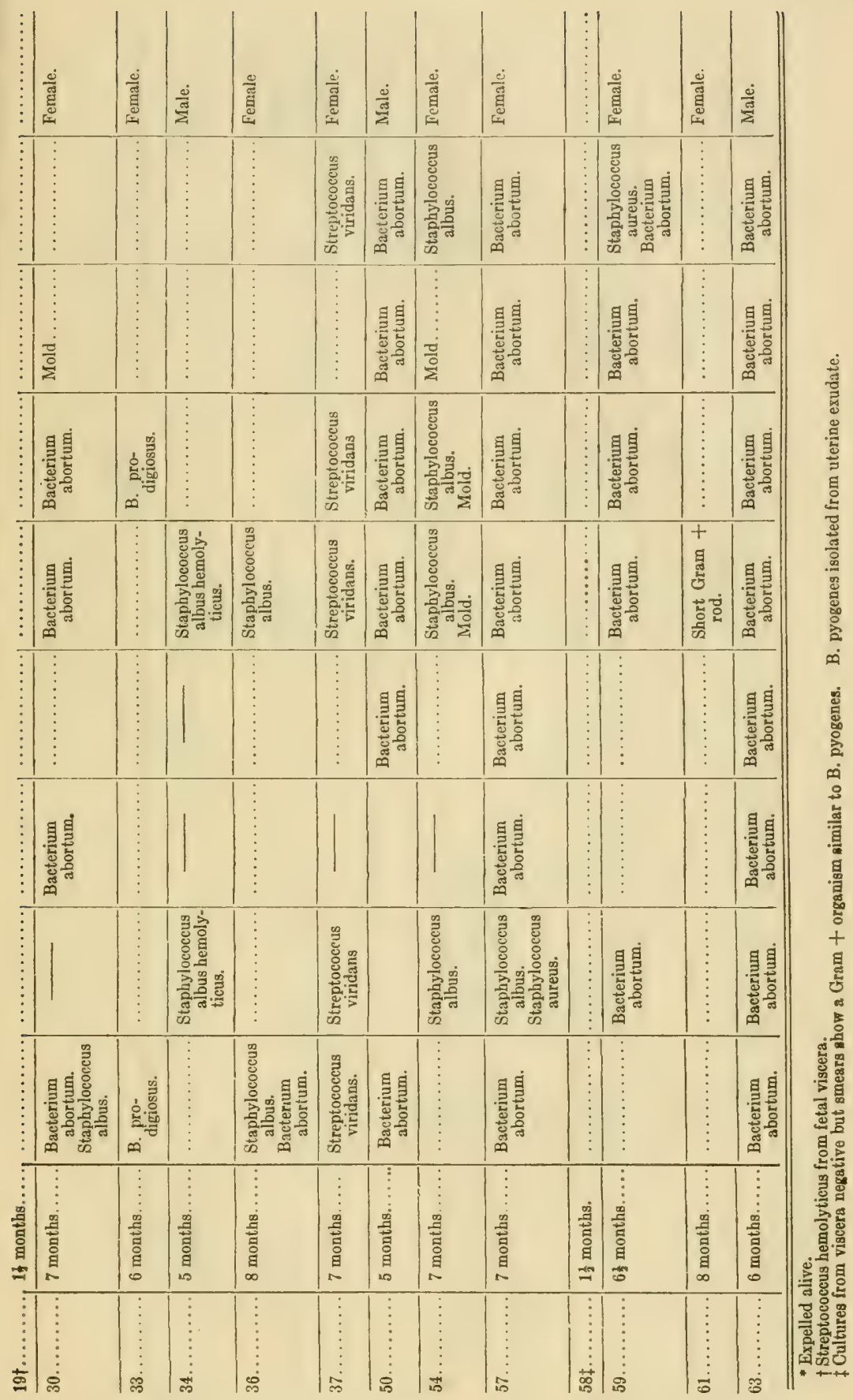




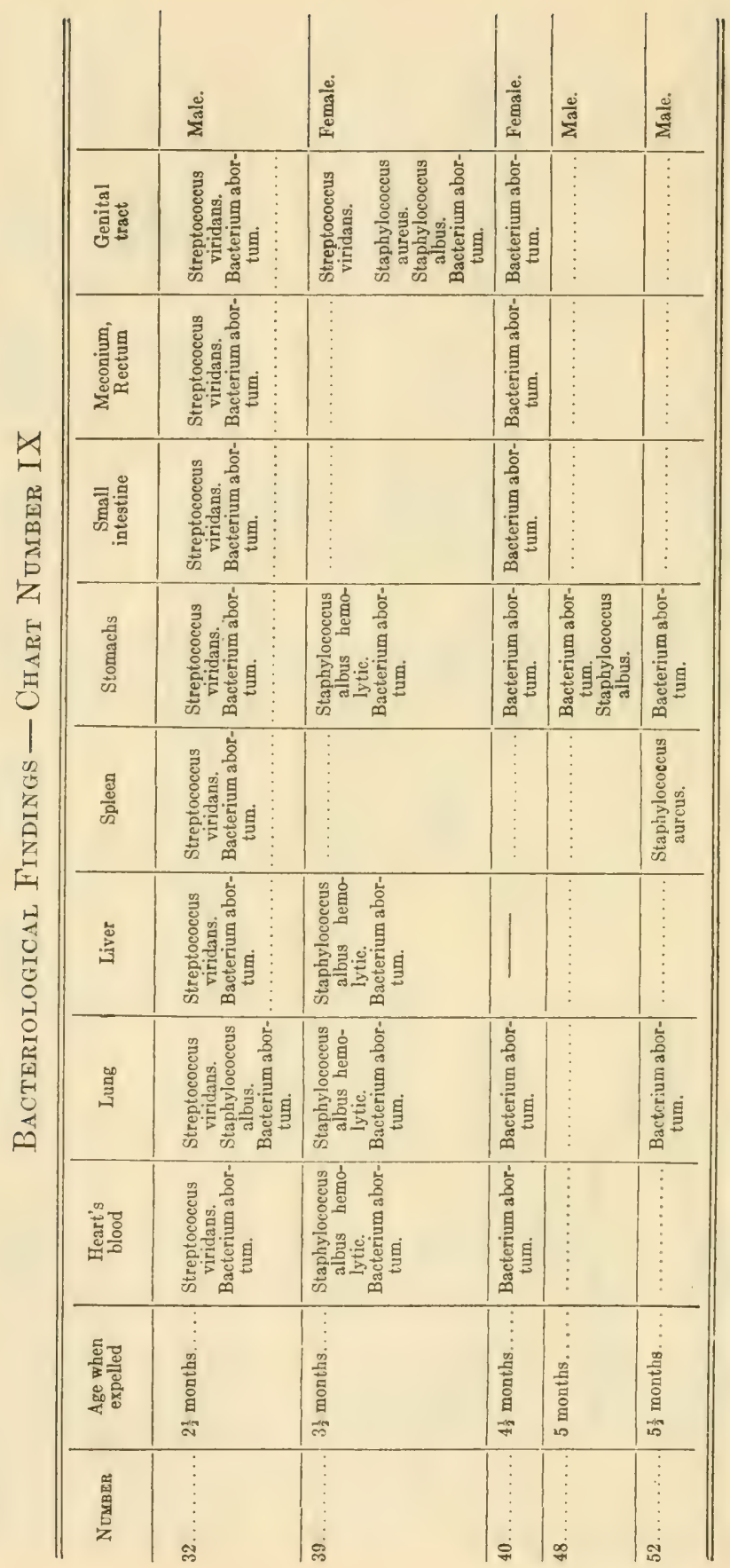




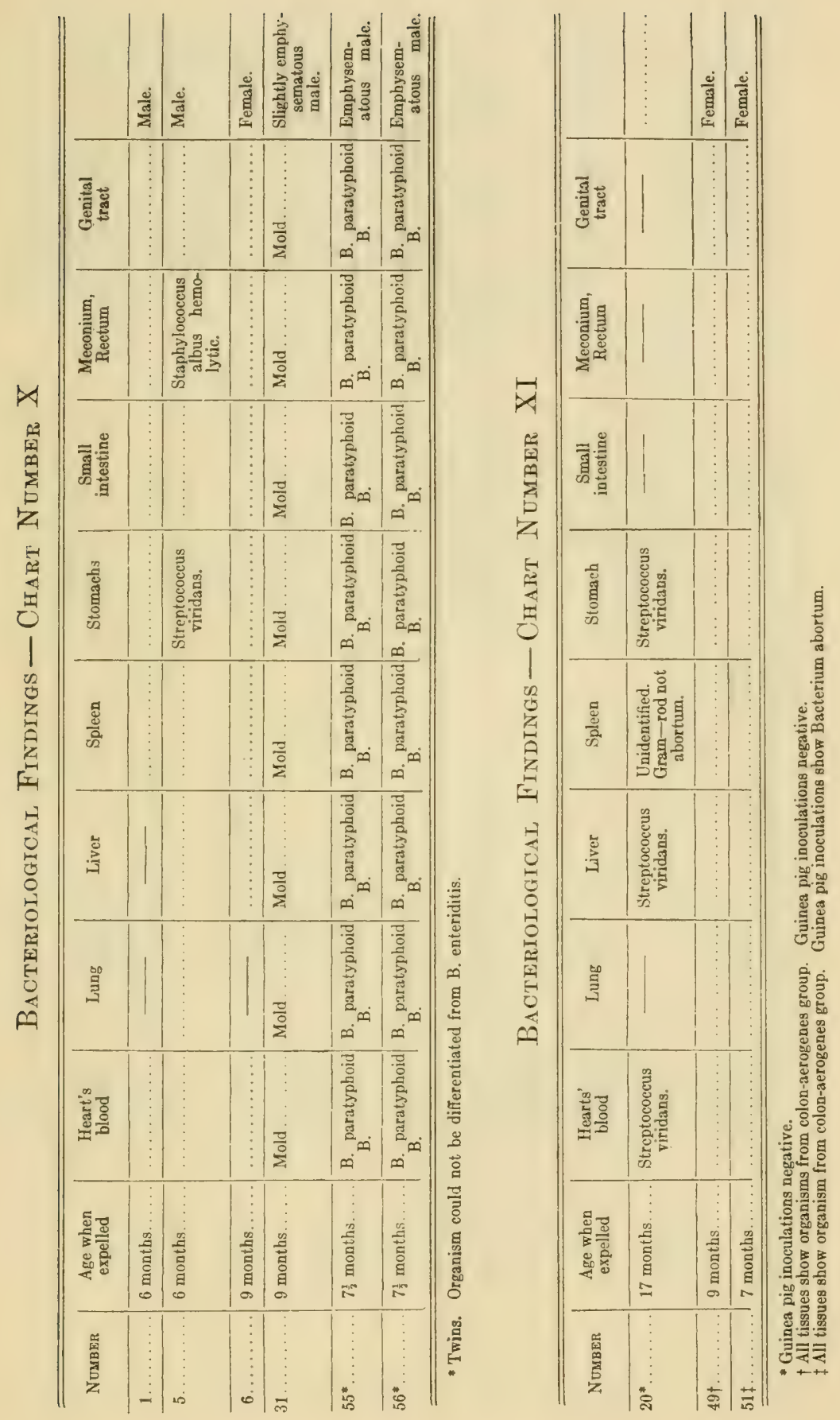




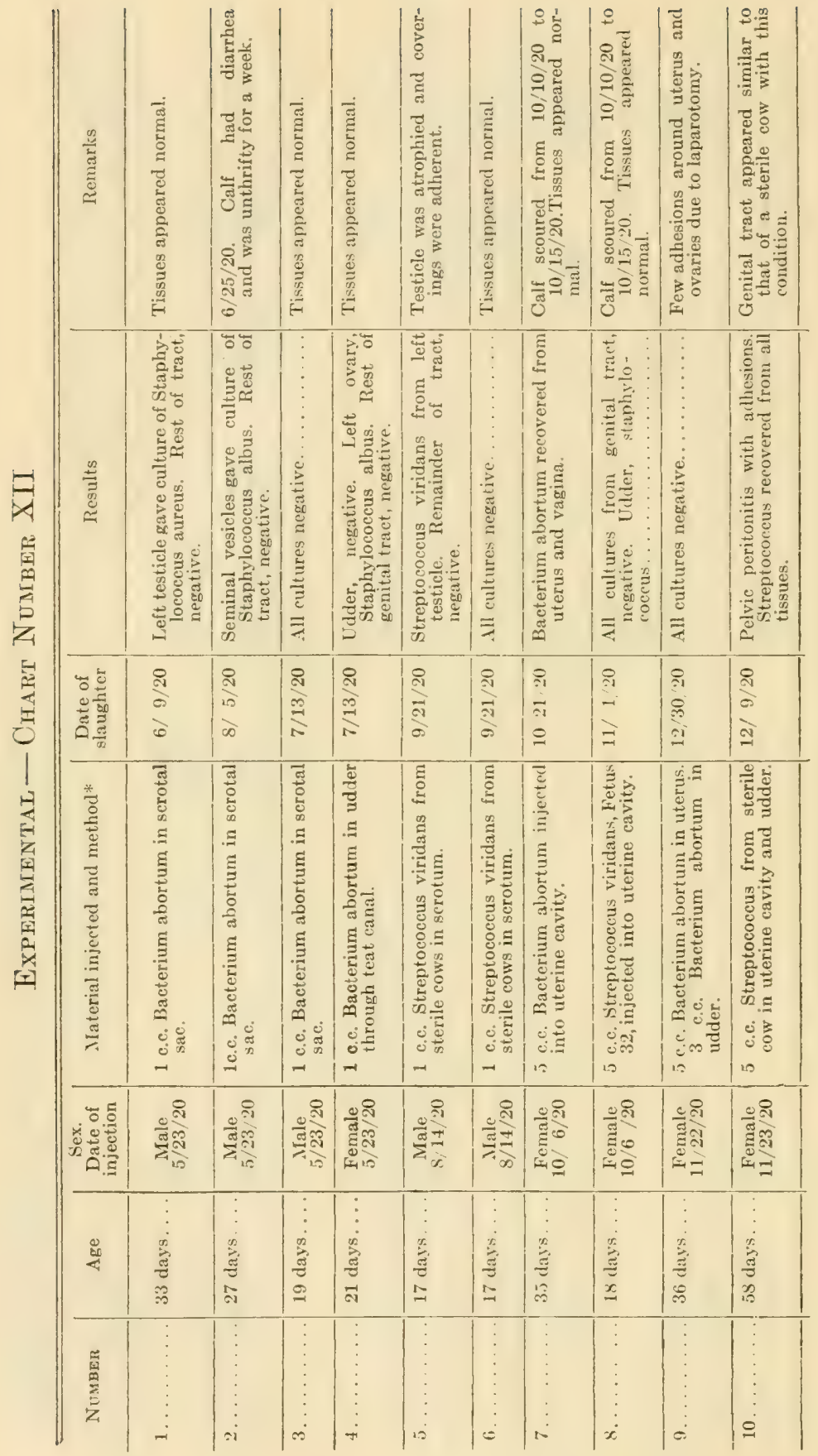




\begin{tabular}{|c|c|c|c|c|c|c|c|c|}
\hline 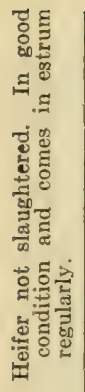 & 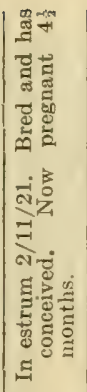 & 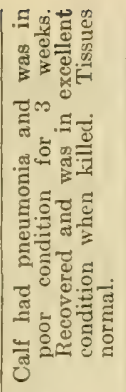 & 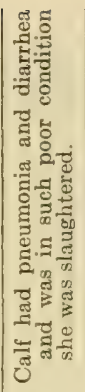 & 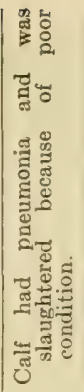 & 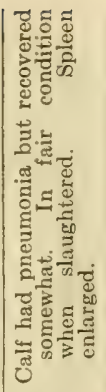 & 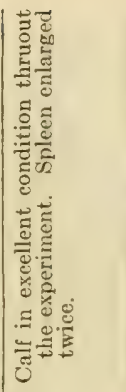 & 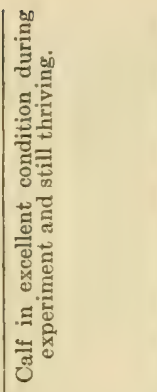 & 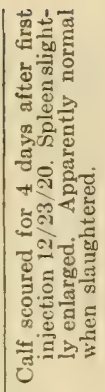 \\
\hline & & 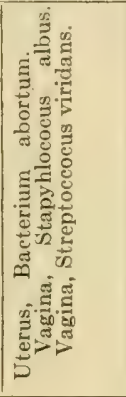 & 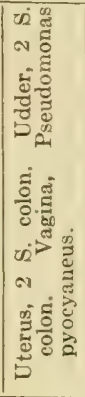 & 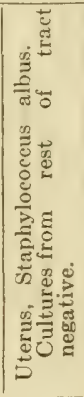 & 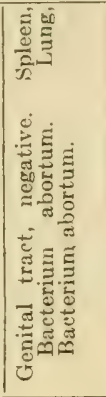 & 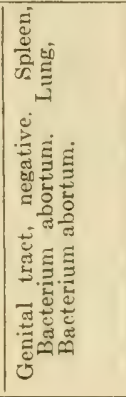 & & 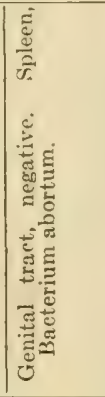 \\
\hline$\vdots$ & & 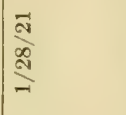 & 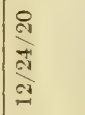 & 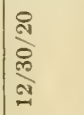 & $\begin{array}{l}-1 \\
-1 \\
\end{array}$ & $\mid \begin{array}{l}\vec{N} \\
- \\
-\end{array}$ & & $\mid \begin{array}{l}\frac{\pi}{2} \\
-\end{array}$ \\
\hline 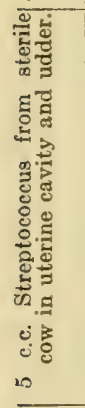 & 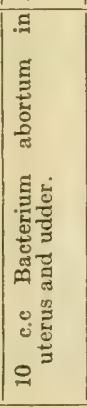 & 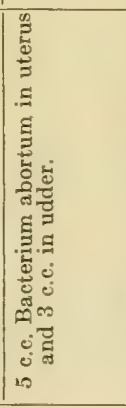 & 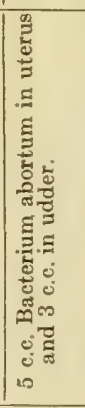 & 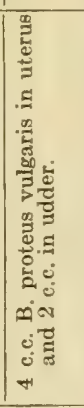 & 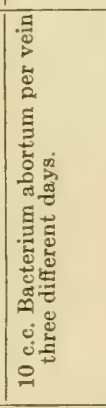 & 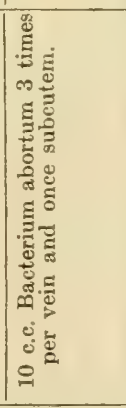 & 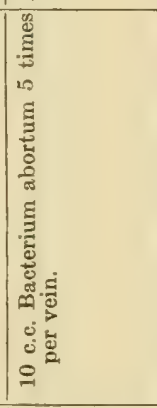 & 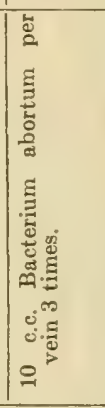 \\
\hline 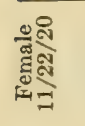 & 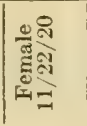 & 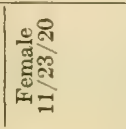 & 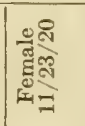 & 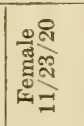 & 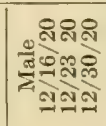 & 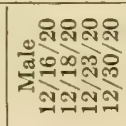 & 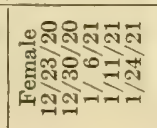 & 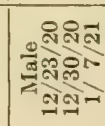 \\
\hline 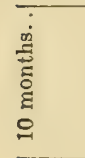 & 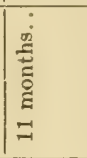 & $\begin{array}{l}\text { Do } \\
\text { is } \\
\text { is } \\
\text { in }\end{array}$ & $\begin{array}{l}\infty \\
\substack{\infty \\
c} \\
\infty \\
\infty\end{array}$ & 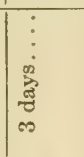 & 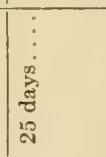 & 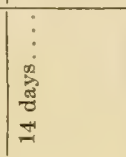 & | & 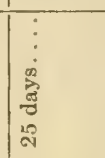 \\
\hline$\vdots$ & $\cong$ & $\cong$ & $\exists$ & 12 & $\stackrel{0}{-1}$ & $1 \approx$ & $\infty$ & 9 \\
\hline
\end{tabular}




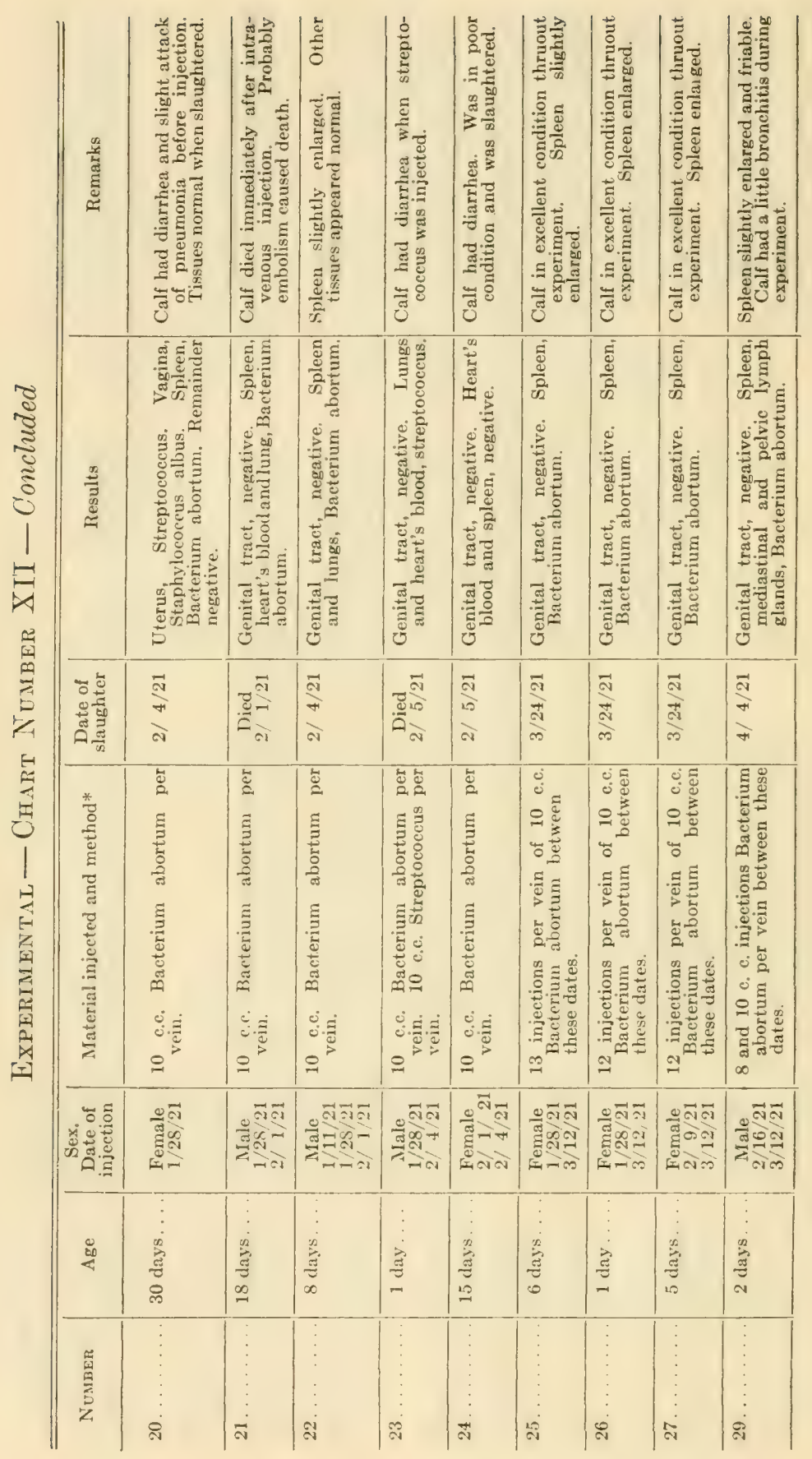




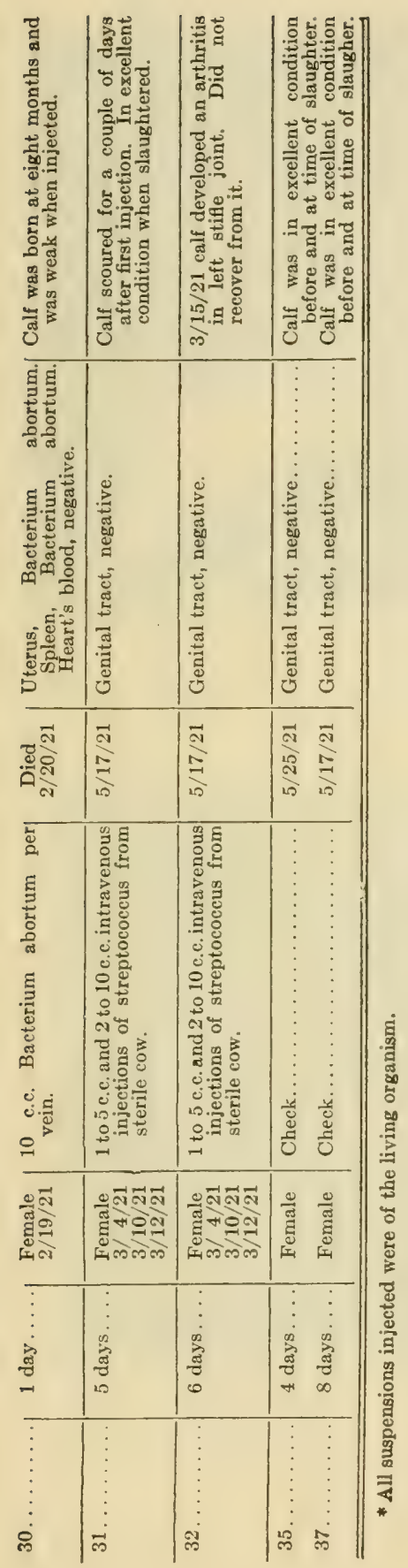





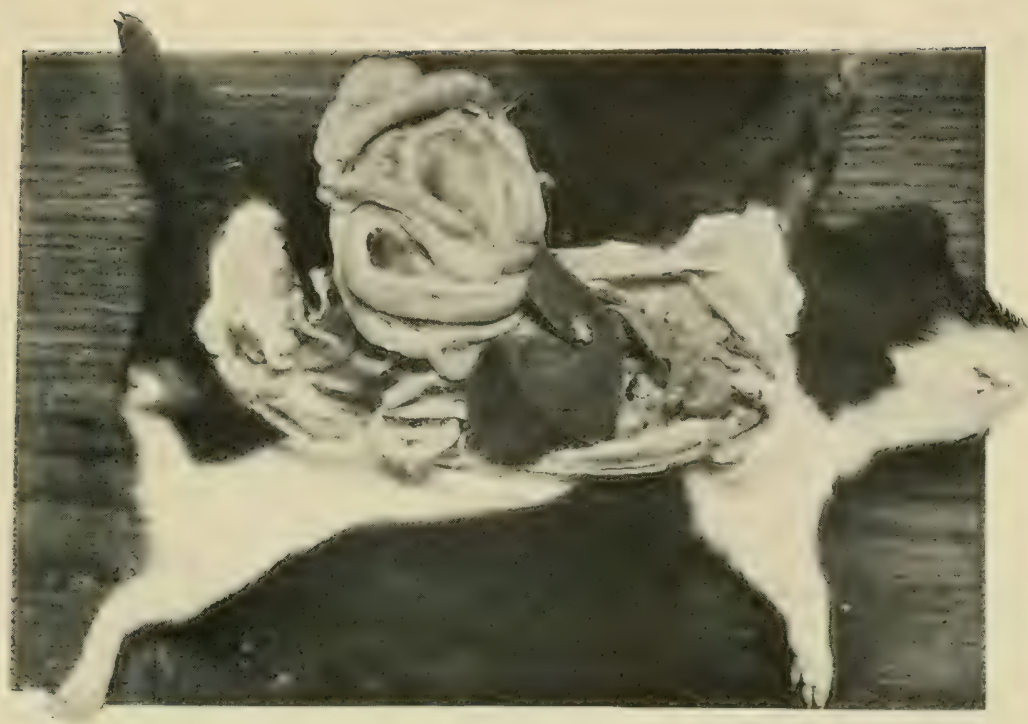

A. Cininea pig fastened to hoard ly means of slanted nail points which pierese the legs. Viscera are exposed for examination.

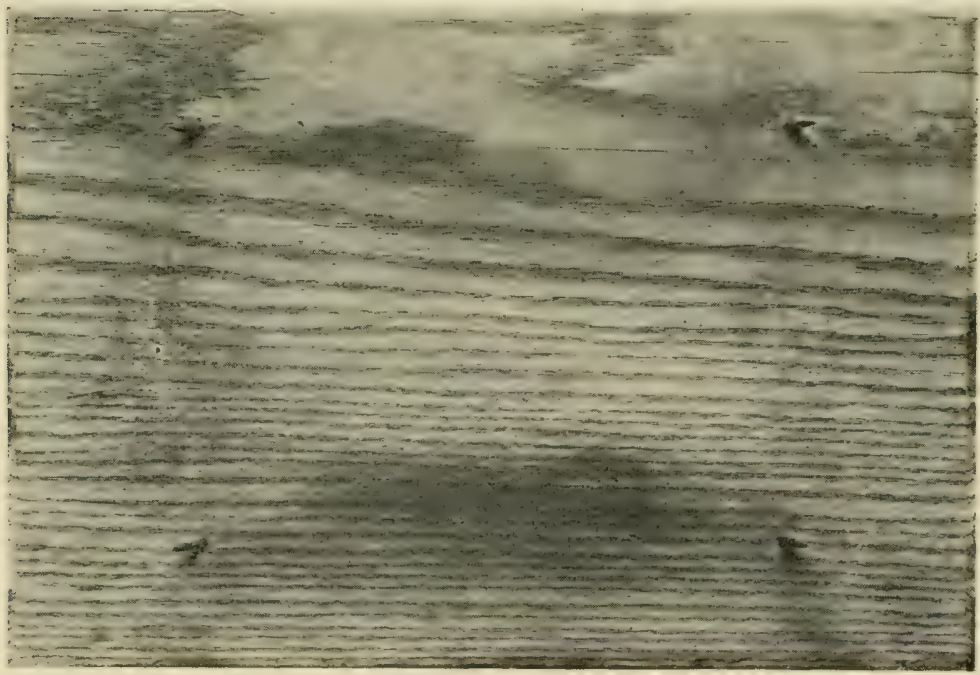

B. Board, $81 / 2 " \times 6^{\prime \prime} \times 1 "$, upon which guinea pigs were fastened after being killed with gas. 

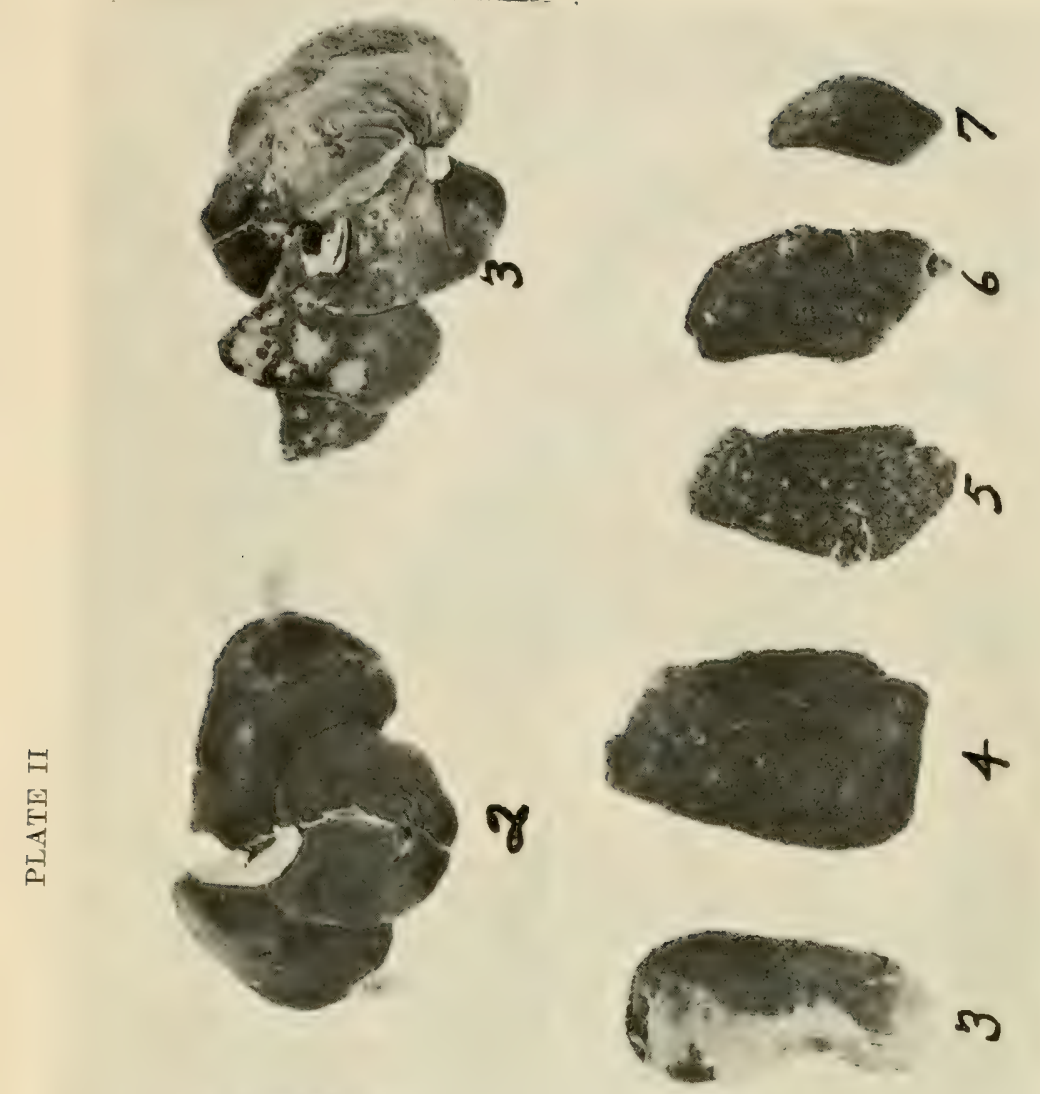

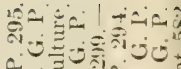

A 100

oi 0.3

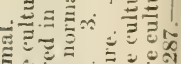

(20)

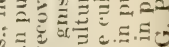

क.

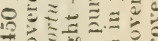

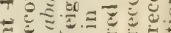

हc

就।

空

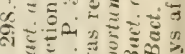

क.

एँ

-

政

है

จ

$+\frac{3}{3}$

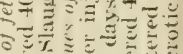

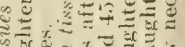

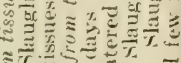

है⿴囗十

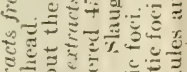

m

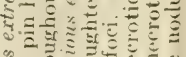

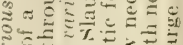
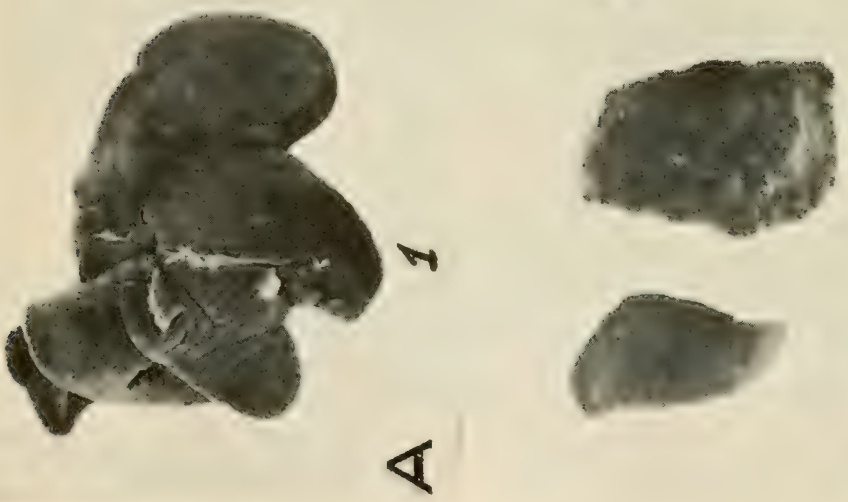

$r$

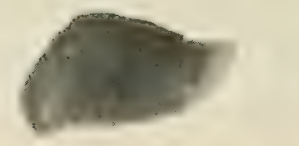

ह

引ँ

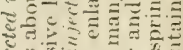

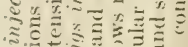

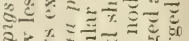

2.

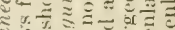

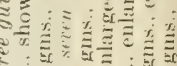

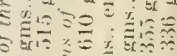

$\rightarrow$

镍

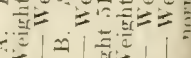

a

1 落 


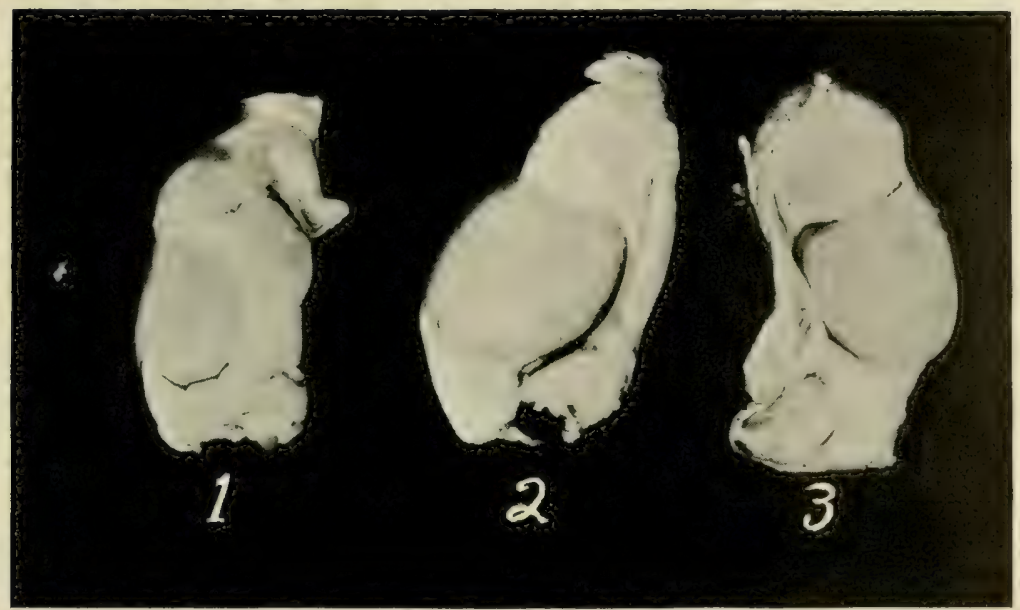

Testes of two guinea pigs injected respectively with extracts from Fetus 62 and placental extraots. 1 and 2. G.. P. 296.-Weight 662 gms. 1. Shows that testicular tissue has atrophied while the epididymis is enlarged and contains abscesses. 2. Right testicle and epididymis are normal. Slaughtered 45 days after injection. Bact. abortum recovered from epididymis of 1 . 3. G. P. 234. - Weight 600 gms., testicle normal. Epididymis contains abscesses from which $\boldsymbol{b}$ (tct. abortum was recovered. Slaughtered 41 days after injection. 


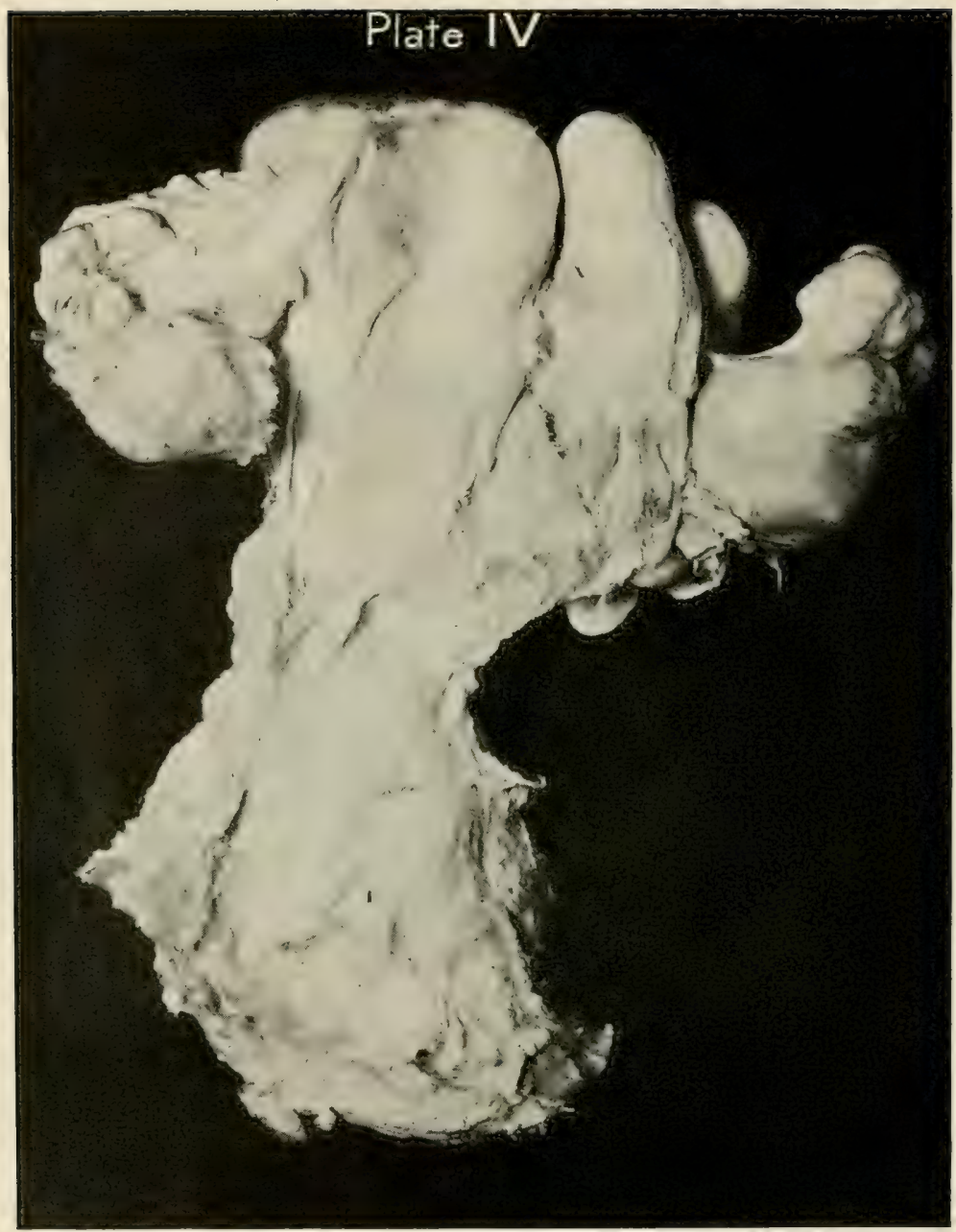

Diseased genital tract, mumber 67 , showing ovaritis, parilionitis, hydro. salpinx and perimetritis. This tract is typical of those from which streptococei have been isolated. 


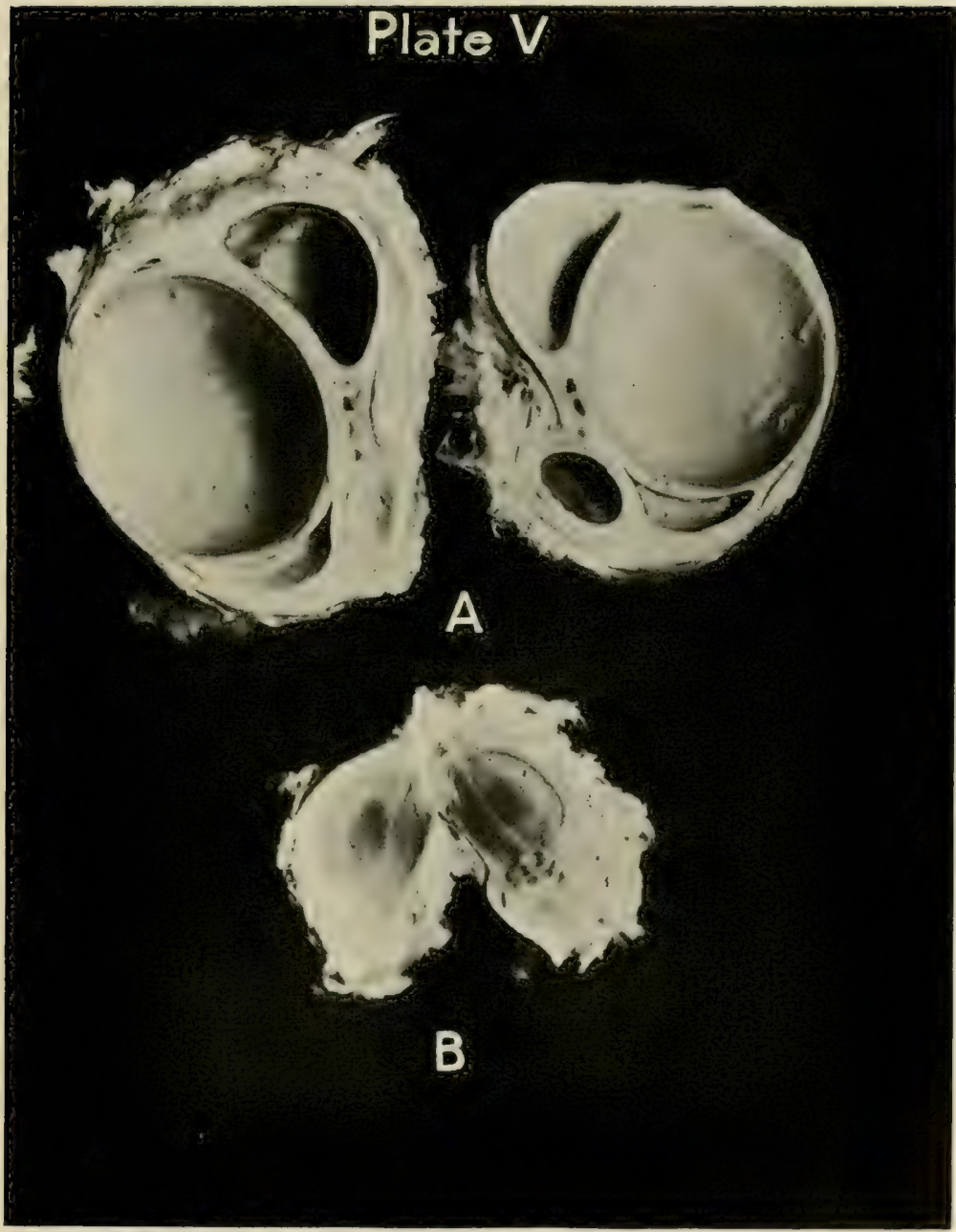

A. Cross sections of eystic right orary of number 66 from which a hemolytic streptococous (Beta) was isolated in pure culture. B. Cross sections of embedded corpus lutem in left ovary of number 67 from which a streptococcus "alpha prime" was isolated in pure culture. 


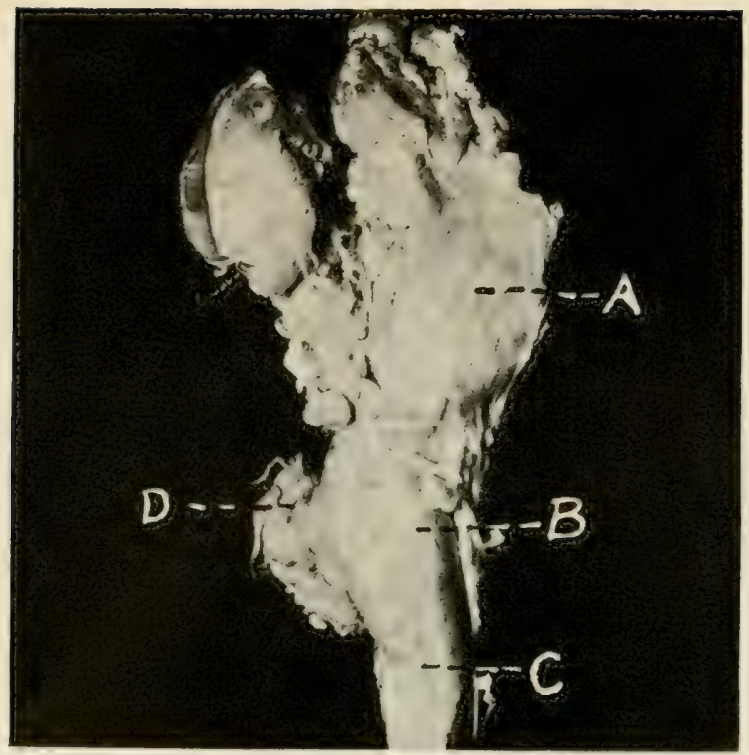

A. Genital tract of Experimental Calf 10 which was injected with Streptococus viridans from the genital tract of a sterile cow. A. Wass of fat adherent to horns of uterus. B. Uterine horns. C. Body of uterus. D. Ovary and pavilion adherent in mass to left uterine horn.

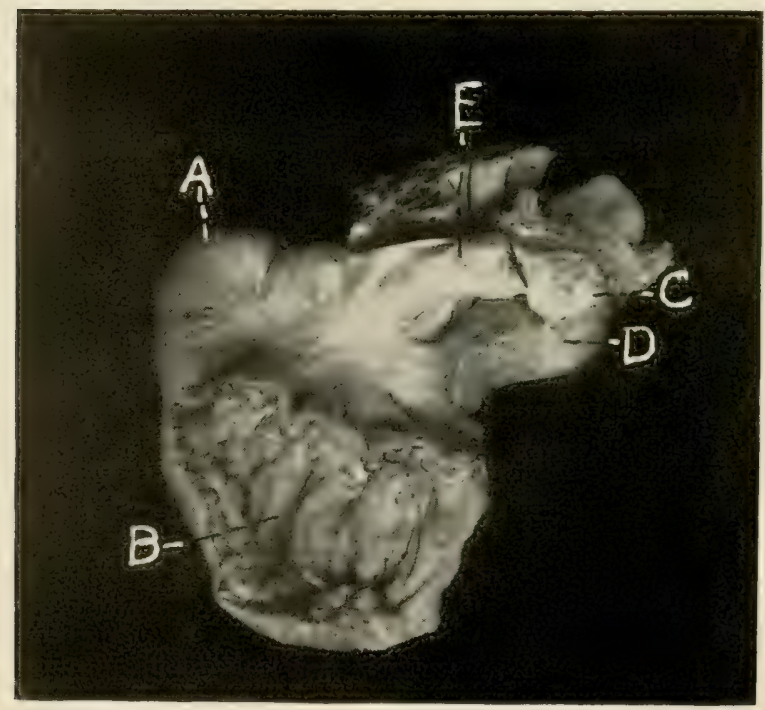

B. Right uterine apex, right oviduet and ovary of Pregnant Uterus 11, pregnant 29 days. Pavilion is adherent to corpus luteum of pregnancy and other areas on the capsule of the ovary. The tube is cystic. Adhesions have formed since ovulation. A. Right uterine apex. B. Endometrium (incision has been made in wall of uterine lorn). C. Pavilion adherent to corpus luteum of pregnancy. D. Corpus luteum of pregnancy. E. Cystic tube. 


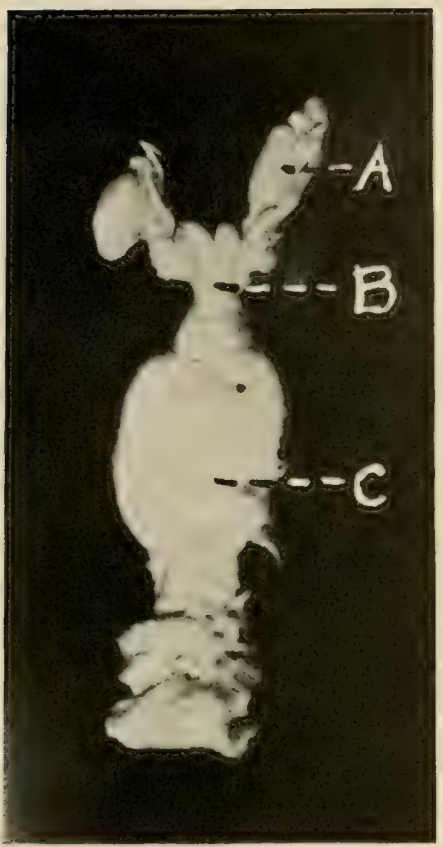

A. Genital tract, 8 'm. long, of Fetus 46 , showing the vavina greatly distended with mucus. $\times 4$.
A. Right ovary.
B. Body of uterus.
C. Vagina.

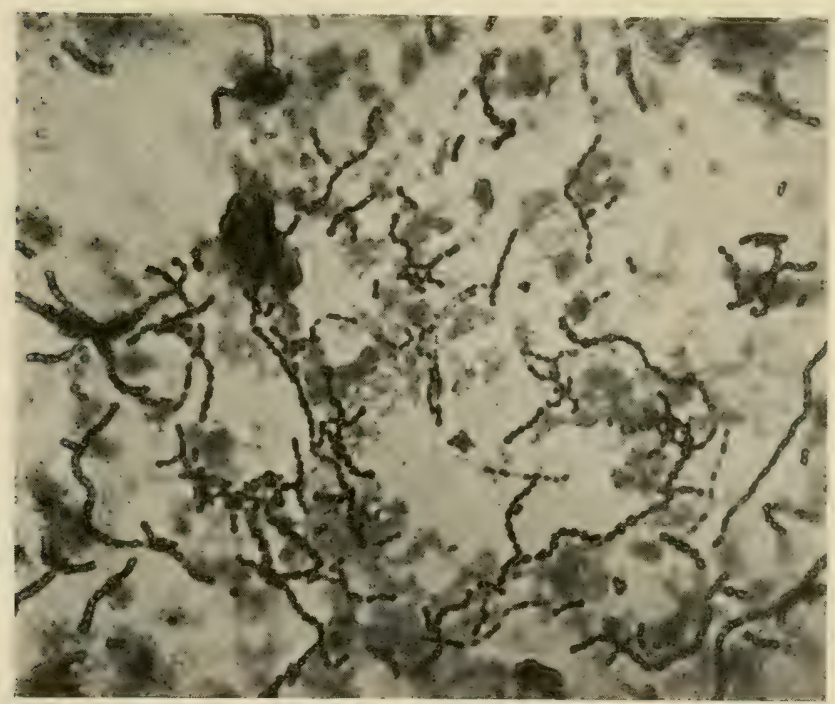

B. Smear made from 24 hr. agar culture of a Streptococous viridans recovered from ovaries and adhesions surrounding them of diseased genital tract of number 65 . 







LIBRARY OF CONGRESS

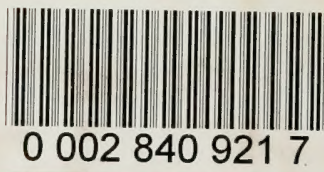

is 